\title{
Novel epi-virotherapeutic treatment of pancreatic cancer combining the oral histone deacetylase inhibitor resminostat with oncolytic measles vaccine virus
}

\author{
TIM PATRICK ELLERHOFF ${ }^{1}$, SUSANNE BERCHTOLD ${ }^{1}$, SASCHA VENTURELLI $^{1}$, \\ MARKUS BURKARD $^{1}$, IRINA SMIRNOW ${ }^{1}$, TANJA WULFF ${ }^{2}$ and ULRICH M. LAUER ${ }^{1}$ \\ ${ }^{1}$ Department of Internal Medicine I, University Hospital Tuebingen, D-72076 Tuebingen; \\ ${ }^{2} 4$ SC AG, D-82152 Planegg-Martinsried, Germany
}

Received May 30, 2016; Accepted July 22, 2016

DOI: 10.3892/ijo.2016.3675

\begin{abstract}
Oncolytic viruses (OV) constitute highly promising innovative biological anticancer agents. However, like every other antitumoral compound, OV are also faced with both primary and secondary mechanisms of resistance. To overcome those barriers and moreover amplify the therapeutic potential of $\mathrm{OV}$, we evaluated a novel combined approach composed of the oral histone deacetylase inhibitor resminostat and an oncolytic measles vaccine virus $(\mathrm{MeV})$ for a future epi-virotherapy of pancreatic ductal adenocarcinoma. Cytotoxicity assays revealed that combined epi-virotherapeutic treatment of four well-characterized human pancreatic cancer cell lines resulted in a beneficial tumor cell killing as compared to either monotherapeutic approach. Notably, epi-virotherapeutic treatment of MIA PaCa-2 and partly also of PANC-1 pancreatic cancer cells resulted in a tumor cell mass reduction being significantly more pronounced than it would be expected in case of an additive effect only, indicating a synergistic mode of action when combining resminostat with $\mathrm{MeV}$. We further found that the epigenetic compound resminostat neither impaired $\mathrm{MeV}$ growth kinetics nor prevented the activation of the interferon signaling pathway which plays an important role in mediating primary and secondary resistances to OV. Moreover, we yielded information that the pharmacodynamic function of resminostat was presumably not altered in the course of pancreatic cancer cell infections with $\mathrm{MeV}$. Taken together, these promising results favor the onset of epi-virotherapeutic clinical trials in patients suffering from advanced pancreatic ductal adenocarcinoma.
\end{abstract}

Correspondence to: Professor Ulrich M. Lauer, Department of Internal Medicine, Division of Hepatology, Gastroenterology, Infectiology, University Hospital Tuebingen, Otfried-Mueller-Str. 10, D-72076 Tuebingen, Germany

E-mail: ulrich.lauer@uni-tuebingen.de

Key words: oncolytic virus, histone deacetylase inhibitor, measles, resminostat, epi-virotherapy

\section{Introduction}

Oncolytic viruses (OV) exhibit unique features such as: i) outstanding safety profiles (especially when vaccine-derived viral vectors are coming to application), ii) high levels of tumor selectivity, iii) an incomparable self-amplification property, iv) lack of cross-resistance with other anticancer drugs (e.g., chemotherapeutic compounds), v) superior capabilities of targeting cancer stem cells as well as, vi) distant metastases and the possibility, vii) to significantly impair the blood supply to tumor beds (1-5).

Recently, OV have made their breakthrough with respect to their implementation in daily clinical practice. Due to the favourable results of the herpes simplex virus type 1 (HSV-1)-derived virotherapeutic vector Imlygic ${ }^{\circledR}$ in a recent phase III clinical trial with patients exhibiting advanced stage melanoma (6), its approval has to be regarded as a hallmark in the clinical development of virotherapy (7). Beyond that, the unique properties of $\mathrm{OV}$ as self-amplifying agents that selectively infect and kill cancer cells have been successfully exploited in the treatment of patients suffering from multiple myeloma resulting in an impressive case with long-term tumor remission following a single shot, high-dose application of a marker gene-encoding recombinant measles vaccine virus (MeV-NIS) (8).

Despite these promising results, OV still have to face several limitations before taking full advantage of their great potential to kill cancer cells. On the one hand, OV like any other viruses are recognized as pathogens facing efficient elimination by the host immune system (9). On the other hand, numerous cancer cell types have been shown to be resistant toward virus-mediated oncolysis due to features such as entry receptor down-regulation as well as an insufficient extent of inactivation of anti-viral signaling pathways in the tumor cells (10-12). In this context, we have revealed that $50 \%$ of the cell lines being represented in the well-characterized NCI-60 tumor cell panel display unwanted mid and high grade resistance toward MeV-mediated oncolysis (13).

In order to address the limitations and with further respect to the advantage that there are no cross-resistances of $\mathrm{OV}$ with other therapeutic regimens, researchers have been prompted by 
the rationale of combining $\mathrm{OV}$ with other anticancer agents, including histone deacetylase inhibitors (HDACi) (recently reviewed in refs. 14,15). The impact of HDACi on cancer cells was found to be highly diversified in terms of mechanisms of action, eliciting induction of apoptosis, causing accumulation of reactive oxygen species as well as inhibiting angiogenesis and metastasis $(16,17)$. Thereby, HDACi almost selectively affect tumor tissues, while sparing healthy cells (17). As a consequence, a reciprocal amplification of antitumoral effects was hypothesized for putative HDACi plus OV combination regimens. In line with this, epi-virotherapeutic strategies already have proven to effectively boost tumor cell killing when compared with either monotherapeutic efficiencies $(14,18-23)$, raising the novel term 'epi-virotherapeutic approach' (24).

Regarding the underlying molecular mechanisms of such epi-virotherapy concepts, several steps of virus-mediated oncolysis can be augmented by HDACi (Fig. 1). Among them, an HDACi-induced impairment of a proper anti-viral immune response is discussed as a potential synergistic mechanism as it is assumed to highly facilitate both virus replication and virus spreading (14). Since HDAC activity is involved in almost every step of the interferon (IFN) pathway, particularly in the transcription of IFN- $\beta$, activation of signal transducers and activators of transcription (STAT) proteins, IFN-stimulated gene factor 3 (ISGF3) formation and ultimately expression of IFN-stimulated genes (ISGs) (25-29), HDACi like VPA and TSA were shown to blunt this cellular anti-viral response $(30,31)$. Moreover, in xenograft models it was shown that T-cell and NK-cell mediated anti-viral immune responses can be significantly impaired by concomitant treatment with entinostat (MS-275) and VPA $(21,23)$. Since virus entry receptors are often epigenetically downregulated in different tumor cells, HDACi were shown to restore coxsackie- and adenovirus receptor (CAR) as well as the human reovirus receptor junctional adhesion molecule-1 (JAM-1) on tumor cell surfaces, thereby significantly increasing rates of primary infections with OV (14,32-34). Furthermore, several OV including vesicular stomatitis virus (VSV) and $\mathrm{MeV}$ have been spotted to profit from an HDACi-related enhancement of autophagy (35-37), displaying a cellular catabolic process that serves: i) for the degradation of cellular components being no longer in general use and ii) for the maintenance of energy levels in times of starvation and cellular stress (38). At last, both the translocation of OV genomes to the cell nucleus via microtubules and the expression of viral genes can be amplified by concomitant HDACi treatment $(15,30,39)$.

$\mathrm{OV}$ derived from the measles virus vaccine strain Edmonston have been extensively investigated in numerous preclinical and clinical studies and have been found to constitute well suited anticancer agents (40-42). During the decades-long use as a vaccine, its safety has been comprehensively verified, whilst a reversion to wild-type $\mathrm{MeV}$ followed by any potential outbreak of harmful $\mathrm{MeV}$ infections has not been documented at any time in history (43).

We studied the antitumoral potential of combining the oral HDACi resminostat with oncolytic $\mathrm{MeV}$ in terms of a future epi-virotherapy of advanced pancreatic adenocarcinoma, a tumor entity which is still tainted with a poor prognosis (44). Resminostat is a hydroxamic acid-based HDACi, inhibiting selectively class I, IIb and IV HDAC enzymes and has already been subject of different successful clinical trials, underlining not only its efficiency, but also its safety and tolerability $(42,45,46)$. We further report that our novel epi-virotherapeutic combination of resminostat with oncolytic $\mathrm{MeV}$ resulted in an enhanced tumor cell killing in human pancreatic cancer cells. Most interestingly and in contrast to the hitherto prevailing opinion, this boostering effect was found not to be related to a resminostat-induced impairment of the anti-viral IFN response.

\section{Materials and methods}

Cell culture and non-viral compounds. Human pancreatic cancer cell lines AsPC-1, MIA PaCa-2, and PANC-1 were purchased from the European Collection of Authenticated Cell Cultures (ECACC); cell line BxPC-3 was obtained from the American Type Culture Collection (ATCC); Vero cells were obtained from the German Collection of Microorganisms and Cell Cultures (DSMZ, Braunschweig, Germany). The cells were kept in a humidified incubator at $37^{\circ} \mathrm{C}$, containing $5 \% \mathrm{CO}_{2}$ and cultured in Dulbecco's modified Eagle's medium (DMEM; Sigma-Aldrich, Munich, Germany) supplemented with $10 \%$ fetal calf serum. Resminostat was kindly provided by 4SC AG (Planegg-Martinsried, Germany).

Propagation and titration of measles vaccine virus. Construction of recombinant measles vectors MeV-GFP (measles vector encoding for green-fluorescent protein as a marker gene integrated into the viral genome) has been described (47). Virus stocks were prepared in Vero cells. For this purpose, $1 \times 10^{7}$ Vero cells were seeded in $15-\mathrm{cm}$ plates. The next day, cells were washed once with phosphate-buffered saline (PBS; Sigma-Aldrich) and infected for $3 \mathrm{~h}$ at a MOI of 0.03 in infection medium (Opti-MEM; Gibco; Grand Island, NY, USA). Subsequently, medium was replaced with DMEM containing $10 \%$ FBS. After an incubation period of $54 \mathrm{~h}$, when most of the cells were infected, medium was removed and attached Vero cells were scraped into $1 \mathrm{ml}$ Opti-MEM. Release of virus was achieved by one freeze-thaw cycle. After centrifugation $\left(1,900 \times \mathrm{g}\right.$, for $15 \mathrm{~min}$ at $\left.4^{\circ} \mathrm{C}\right)$, supernatants were stored at $-80^{\circ} \mathrm{C}$. Viral titers were determined on Vero cells according to the method of Spearman (48) and Kärber (49).

Infection of cells with measles vaccine virus. Cells were seeded in 6- or 24-well plates the day before virus infection. Then, culture medium was removed, cells were washed with PBS and subsequently virus was diluted in Opti-MEM at required multiplicities of infection (50) was added. After $3 \mathrm{~h}$ of incubation, the inoculum was removed and DMEM supplemented with $10 \%$ FCS and, if required additionally resminostat was added.

SRB assay. For SRB assay cells were seeded in 24-well plates with cell numbers ranging from $2 \times 10^{4}$ for $\mathrm{MIA} \mathrm{PaCa}-2$ to $3 \times 10^{4}$ for PANC-1 and $4 \times 10^{4}$ per well for AsPC-1 and BxPC-3. Experiments were stopped at required time-points after treatment by removing medium, washing with PBS and subsequently fixing with trichloroacetic acid $\left(10 \%, 4^{\circ} \mathrm{C}\right.$ for $\left.30 \mathrm{~min}\right)$. Afterwards, fixed cells were washed four times with tap water, 


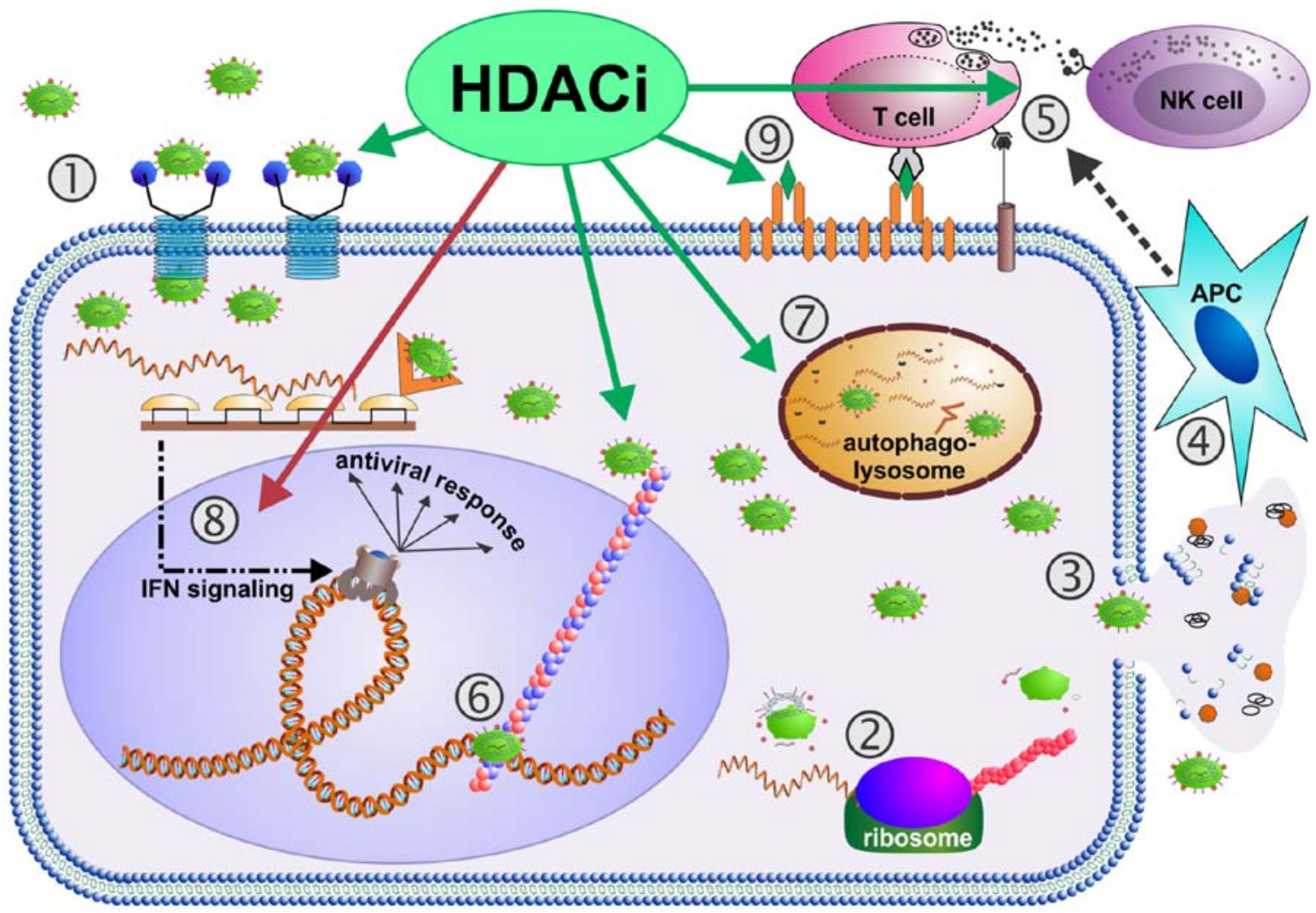

Figure 1. Virus-induced oncolysis augmented by histone deacetylase inhibitors (HDACi). Following receptor binding (1), oncolytic viruses (OV) infect tumor cells. Then, host cell ribosomes are occupied with translation of viral RNA into viral structural/functional proteins (2), resulting in generation of numerous progeny viral particles per single host tumor cell. This enormous replicative process ends up in complete exhaustion of host tumor cells, inescapably leading to tumor cell disintegration, i.e., viral oncolysis. Thereby, not only newly produced viral particles are released (3), but also tumor-associated antigens (TAAs) and damage-associated molecular pattern molecules (DAMPs), which are detected by antigen-presenting cells (APCs) (4) (68). Concurrently, OV infection induces production of pro-inflammatory, immune cell-attracting cytokines, which also exert potent antitumor activities (61). Furthermore, OV infections upregulate MHC-I expression on tumor cells (69). Altogether, APC activation, production of antitumor cytokines and upregulation of antigen-presenting receptors are assumed to initiate a powerful $\mathrm{T}$ cell-mediated antitumor immune response (5) (68,70). Notably, all these steps of the viral oncolytic cycle (1-5) can be influenced by histone deacetylase inhibitors (HDACi): first of all, HDACi can upregulate expression of viral entry receptors on tumor cells leading to increased rates of tumor cell infection by OV (1) $(14,32,33)$. Further, translocation of OV genomes, i.e., post-entry shuttling to the nucleus via microtubules (6) can be increased by HDACi (39). Next, expression of viral genes can be augmented by HDACi in tumor cells $(15,30,39)$. HDACi-enhanced tumor cell autophagy (7) can result in increased OV-mediated oncolysis and enhanced induction of tumor cell apoptosis (36). Remarkably, HDACi were also found to be able to dampen antiviral IFN responses being characteristic for OV-resistant tumor cells (8) $(11,12)$, thereby significantly facilitating OV replication and spread $(14,24,30,59)$. In terms of boosting immune cell-mediated antitumor response, HDACi can raise the levels of cytokines being supportive for the functional development of tumor antigen-specific $\mathrm{CD}^{+} \mathrm{T}$ cells (5) (21). Beyond that, HDACi can also inhibit T- and NK cell-mediated antiviral responses, supporting an unimpaired OV replication and propagation in tumor cells $(21,23)$. As HDACi can also cause upregulation of MHC-I molecules, co-stimulatory receptors as well as TAAs (9) $(17,71,72)$, it is tempting to speculate that combined epi(HDACi)-virotherapeutic approaches might further amplify the magnitude of antitumor immune response. Taken together, OV-induced oncolysis can be augmented by HDACi in many steps and on numerous levels of the interaction between host tumor cells and OV.

dried and then stained with SRB solution $(0.4 \%$ in $1 \%$ acetic acid) for $10 \mathrm{~min}$ at room temperature. After washing with $1 \%$ acetic acid and drying again bound SRB was dissolved in $10 \mathrm{mM}$ Tris base (pH 10.5) and the optical density was measured at a wavelength of $550 \mathrm{~nm}$ using a microplate reader (Tecan Genios Plus). The mean of mock-treated controls was set to $100 \%$ and treated samples were stated in percent of this control.

Real-time cell proliferation assay. Cells were seeded in 96-well plates (E-Plate 96, Roche Applied Science, Mannheim, Germany) in different concentrations according to their particular proliferation characteristics (AsPC-1: $1 \times 10^{4}$ cells/ well; MIA PaCa-2: $7.5 \times 10^{3}$ cells/well; PANC-1: $5 \times 10^{3}$ cells/ well). Real-time dynamic cell proliferation was monitored in 30-min intervals during a 120 -h observation period using the xCELLigence RTCA SP system (Roche Applied Science). Cell index values were calculated using the RTCA Software (1.0.0.0805). At $21 \mathrm{~h}$ after seeding, cells were infected with MeV-GFP diluted in Opti-MEM and at 3 hpi resminostat was added in required concentrations. All values were normalized to the beginning of the treatment period ( $24 \mathrm{~h}$ after seeding) $(51,52)$.

Viral growth curves. Cells were infected with MeV-GFP in 24-well plates. At 3 hpi the inoculum was removed and cells were washed three times with PBS. Then $0.5 \mathrm{ml}$ medium or medium with resminostat were added. At 3, 24, 48, 72 and 96 hpi supernatants were harvested and cells were scraped off in $0.5 \mathrm{ml}$ Opti-MEM. Cell lysis was performed by one freezethaw cycle and subsequently virus titers were determined by titrating samples on Vero cells following Spearman (48) and 
Kärber (49). Therefore, Vero cells were seeded in a density of $1 \times 10^{4}$ cells per well in 96-well plates in DMEM containing $5 \%$ FCS. Twenty-four hours later, cells were infected with 1:10 dilution series generated from cell lysate and supernatant samples. Tissue culture infective dose $\left(\mathrm{TDC}_{50}\right)$ was calculated by observing measles-induced cytopathic effect with a fluorescence microscope and converted into plaque forming units per $\mathrm{ml}(\mathrm{pfu} / \mathrm{ml})$.

Immunoblotting. Protein samples were obtained by seeding, infecting and treating pancreatic cancer cells in 6-well plates. At required time-points, medium was removed, cells were washed with PBS and afterwards harvested in lysis buffer (50 mM Tris- $\mathrm{HCl} \mathrm{pH} 7.6,150 \mathrm{mM} \mathrm{NaCl}, 1 \%$ NP40). Cell lysis was performed by three freeze-thaw cycles. Lysates were then cleared by centrifugation at $13,000 \mathrm{rpm}$ for $10 \mathrm{~min}$. Protein concentrations in the supernatants were determined by Bradford protein assay (Bio-Rad, Hercules, CA, USA).

Each sample $(70 \mu \mathrm{g})$ was mixed with 6-fold Roti Load buffer and boiled at $95^{\circ} \mathrm{C}$ for $5 \mathrm{~min}$. Proteins were separated on a $8 \%$ polyacrylamide gel and blotted on a polyvinylidene difluoride (PVDF) membrane (Amersham Hybond P, GE Healthcare). Membranes were blocked in 5\% powdered milk in Tris-buffered saline containing $0.02 \%$ Tween-20 (TBS-T) and then incubated with primary antibodies (anti-IFIT1: GTX103452; 1:1,000; GeneTex, Irvine, CA, USA; anti-phospho-Stat1: 58D61; 1:1,000; Cell Signaling Technology, Danvers, MA, USA; anti-Stat1: sc-591; 1:500; Santa Cruz Biotechnology, Santa Cruz, CA, USA; anti$\beta$-actin: A 4700; 1:6,000; Sigma-Aldrich) overnight. After washing three times with TBS-T, membranes were exposed to the secondary antibody (goat anti-rabbit IgG; goat anti-mouse IgG; HRP-coupled; Abcam Ltd., Cambridgeshire, UK). After washing three times with TBS-T again proteins were detected by enhanced chemiluminescence western blotting detection reagent (GE Healthcare).

$q P C R$. Cells were treated with resminostat, MeV-GFP or the combination and subsequently RNA was isolated using the NucleoSpin ${ }^{\circledR}$ RNA kit (Macherey-Nagel, Dueren, Germany) according to the manufacturer's instructions.

Each RNA sample (500 ng) was mixed with $2 \mu \mathrm{l}$ M-MLV RT buffer (Promega, Madison, WI, USA), $1 \mu$ l RNase-inhibitor RNasin Plus (Promega), $1 \mu \mathrm{l}$ oligo-dT-Primer $(0.5 \mu \mathrm{g} / \mu \mathrm{l})$ (TIB MolBio, Berlin, Germany), $0.5 \mu \mathrm{l}$ dNTP mix (Roti-Mix PCR3, Carl Roth) and added up to a total volume of $9.6 \mu 1$ in RNAse-free water. Samples were then incubated at $70^{\circ} \mathrm{C}$ for 2 min. After adding $0.4 \mu \mathrm{l}$ reverse-transcriptase M-MLV RT $\mathrm{H}(-)$ Point Mutant (Promega), samples were incubated at $42^{\circ} \mathrm{C}$ for $60 \mathrm{~min}$.

The cDNA samples diluted (1/40) with tRNA- $\mathrm{H}_{2} \mathrm{O}$; primers were used in a concentration of $500 \mathrm{nM}$. PCR was carried out in an iCycler (Bio-Rad) with iQ5 Multicolor Real-time Detection system (Bio-Rad), using the following setup: $10 \mu \mathrm{l}$ iQSYBR Green PCR Master Mix (Promega), $0.1 \mu \mathrm{l}$ of each primer (100 $\mu \mathrm{M}$ stock), $5.8 \mu \mathrm{l} \mathrm{H}_{2} \mathrm{O}$ and $4 \mu \mathrm{l} \mathrm{cDNA}$ (diluted 1/40). The following primer pairs were used: zfp64 (splicing variants $1,3,4)$ forward, ACCTGCCCACGGAA AGTAAT; zfp64 (splicing variants $1,3,4$ ) reverse, TATGGGG TTTGTCTCCCGTG; RPS18 (housekeeping gene) forward,
GAGGATGAGGTGGAACGTGT; RPS18 reverse, TCTTCAG TCGCTCCAGGTCT. PCR was carried out with the following thermal profile: $3 \mathrm{~min}$ at $95^{\circ} \mathrm{C}$ with subsequently 40 cycles for $15 \mathrm{sec}$ at $95^{\circ} \mathrm{C}, 20 \mathrm{sec}$ at $58^{\circ} \mathrm{C}$, and $15 \mathrm{sec}$ at $62^{\circ} \mathrm{C}$. Heating up for $1 \mathrm{~min}$ at $95^{\circ} \mathrm{C}$ was followed by $1 \mathrm{~min}$ at $65^{\circ} \mathrm{C}$ and 81 cycles at $65^{\circ} \mathrm{C}$ cooling down to $20^{\circ} \mathrm{C}$. Target gene expression was evaluated via the $2^{-\Delta \mathrm{Ct}}$ method and normalized to the housekeeping gene RPS18 and subsequently graphed relative to the respective mock sample for each time-point and expressed as 'relative gene expression'.

Statistical analysis. The influence of measles and resminostat on the decadic logarithm of cell mass (in \% of the mean of the cell line control) was examined by performing a two-way analysis of variance (ANOVA). Additionally, an interaction of measles and resminostat was used in the ANOVA. Calculations were done by the JMP software for windows. P-values $<0.01$ were considered to be statistically significant. Graphs including error bars were imaged with GraphPad Prism 4 for windows.

\section{Results}

Dose- and time-dependent effects of resminostat and $\mathrm{MeV}$ on pancreatic cancer cells. Following our encouraging results recently obtained in the epi-virotherapeutic treatment of human hepatoma cells (24), we now examined the antitumor potential of the epi-virotherapeutic approach consisting of the oral HDACi resminostat and $\mathrm{MeV}$ for the therapy of pancreatic ductal adenocarcinoma. For this purpose, we first determined the antitumor effects elicited by each agent in monotreatment on a panel of four human pancreatic cancer cell lines (AsPC-1, BxPC-3, MIA PaCa-2, and PANC-1).

First, tumor cells were treated with resminostat at different concentrations ranging from 0 to $10 \mu \mathrm{M}$. Experiments were stopped at different time-points and tumor cell viabilities were subsequently examined by sulforhodamine B (SRB) assays (Fig. 2).

As a result, treatment with resminostat displayed a doseand time-dependent cytoreductive effect in all investigated human pancreatic cancer cell lines. In detail, MIA PaCa-2 cells were shown to be most sensitive exhibiting a tumor cell mass reduction of almost $100 \%$ at $5 \mu \mathrm{M}$ resminostat at $96 \mathrm{~h}$ posttreatment (hpt). In contrast, PANC-1 cells were shown to be most resistant with a remaining tumor cell mass of $\sim 70 \%$ with $5 \mu \mathrm{M}$ resminostat at $96 \mathrm{hpt}$ (Fig. 2D). For further experiments, concentrations of resminostat were adjusted in a tumor cell line-specific manner ensuring remaining tumor cell masses $\sim 75 \%$ at 96 hpt with resminostat only: $1 \mu \mathrm{M}$ resminostat for tumor cell lines MIA PaCa-2 and AsPC-1, 2.5 $\mu \mathrm{M}$ for BxPC-3 tumor cells, and $5 \mu \mathrm{M}$ for PANC-1 tumor cells, respectively.

Next, all four human pancreatic cancer cell lines were infected with a GFP marker gene-encoding oncolytic measles vaccine virus vector (MeV-GFP) at different multiplicities of infection (50) ranging from 0.25 to 20 (i.e., using a ratio of $0.25-20$ virus particles per single tumor cell to be infected) (Fig. 3). Again, tumor cell viabilities were determined by SRB assays, now at both 72 and $96 \mathrm{~h}$ post infection (hpi). As a result, pancreatic cancer cells displayed great differences in susceptibility towards MeV-GFP-mediated oncolysis. The tumor cell line being most sensitive to MeV-GFP-mediated 
A

AsPC-1

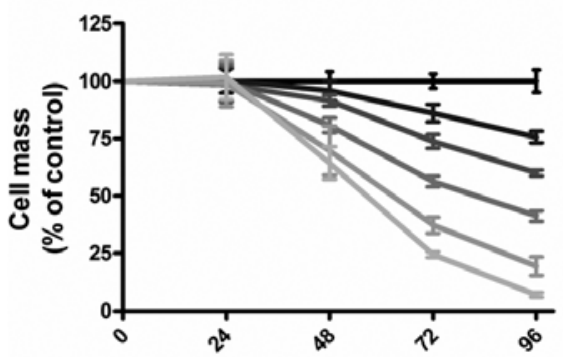

Hours post treatment

C

MIA PaCa-2

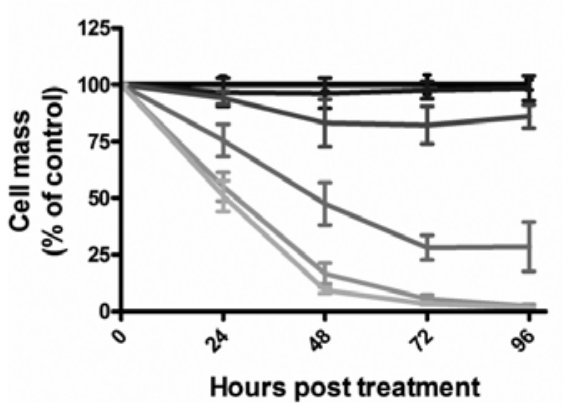

B
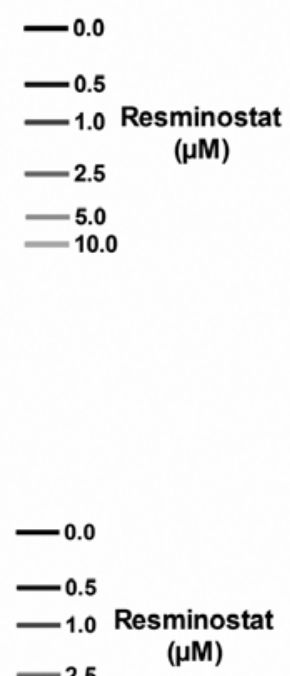

BxPC-3

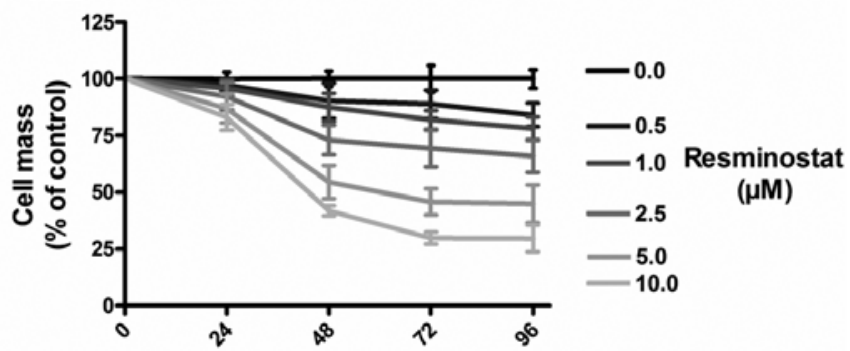

Hours post treatment

PANC-1

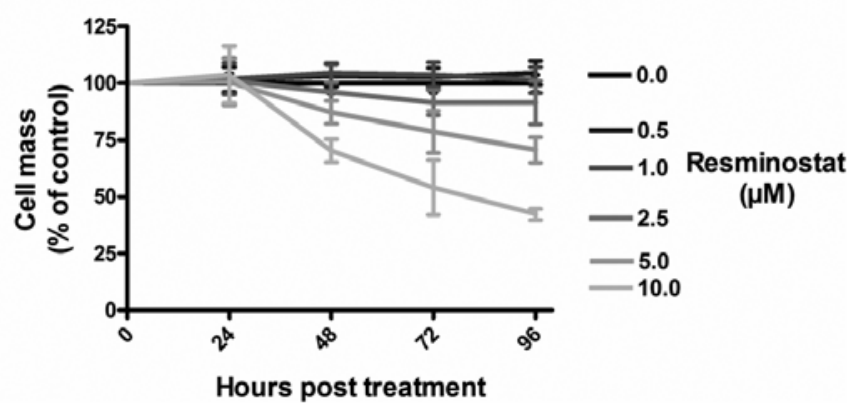

Figure 2. (A-D) Evaluation of resminostat-induced pancreatic cancer cell mass reduction. Mono-treatment with the epigenetic compound resminostat resulted in a dose- and time-dependent reduction of tumor cell masses in all tested pancreatic cancer cell lines (AsPC-1, BxPC-3, MIA PaCa-2 and PANC-1). Six concentrations of resminostat (ranging from 0 to $10 \mu \mathrm{M}$ ) were administered and tumor cell viabilities were determined at four different time-points (24, 48, 72 and $96 \mathrm{~h}$ after treatment) utilizing a Sulforhodamine B (SRB) viability assay. Tumor cell masses are given in \% of the mean of mock-treated tumor cells (resminostat concentration of $0 \mu \mathrm{M}$ ) for each time-point. Means and SDs of three independent experiments are shown.

A

AsPC-1

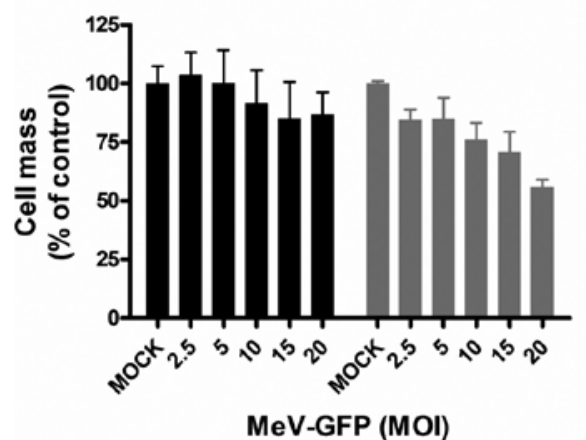

C

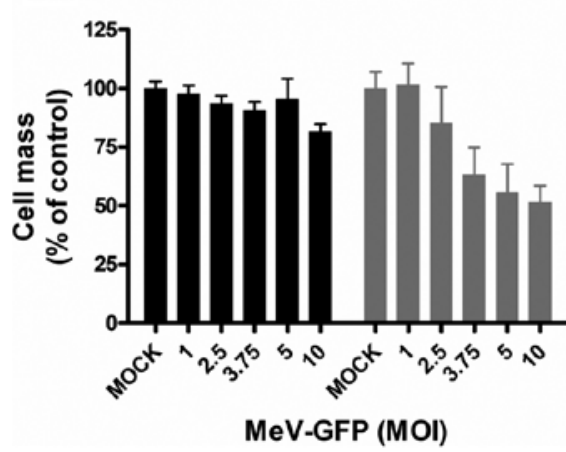

B

BxPC-3
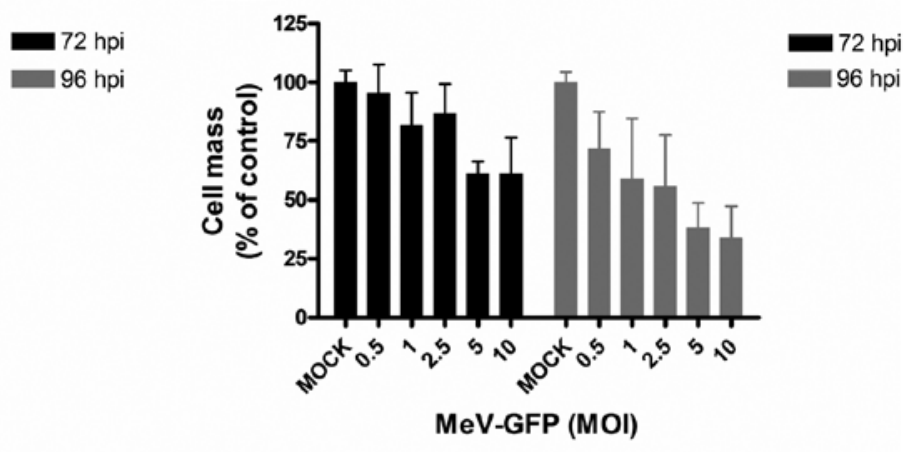

D

PANC-1
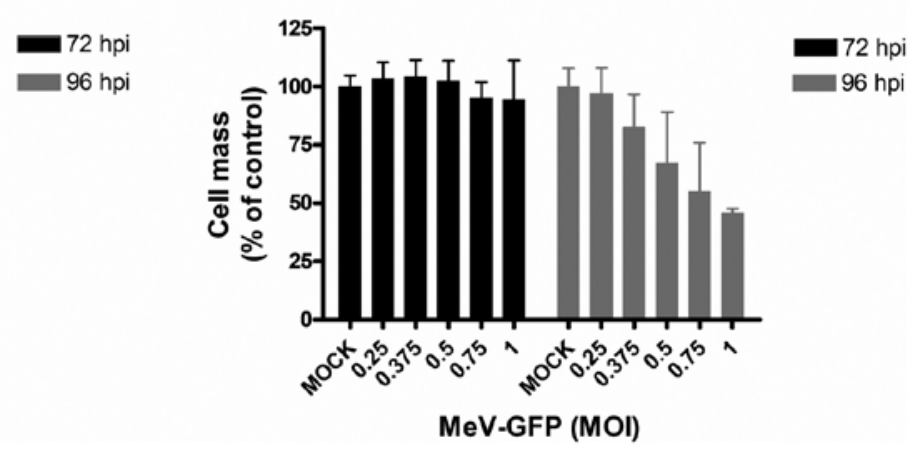

Figure 3. (A-D) Evaluation of MeV-GFP-induced pancreatic cancer cell mass reduction. Mono-treatment with recombined measles virotherapeutics (MeV-GFP) resulted in a dose- and time-dependent reduction of tumor cell masses in all pancreatic cancer cell lines (AsPC-1, BxPC-3, MIA PaCa-2 and PANC-1). Virotherapeutic treatments were performed at indicated multiplicities of infection (50), being adjusted to the oncolytic susceptibility of the respective tumor cell line. Tumor cell viabilities were determined at 72 and $96 \mathrm{~h}$ post-infection (hpi) using SRB viability assays. Tumor cell masses are given in \% of the mean of mock-treated tumor cells for each time-point. Means and SDs of three independent experiments are shown. 
A

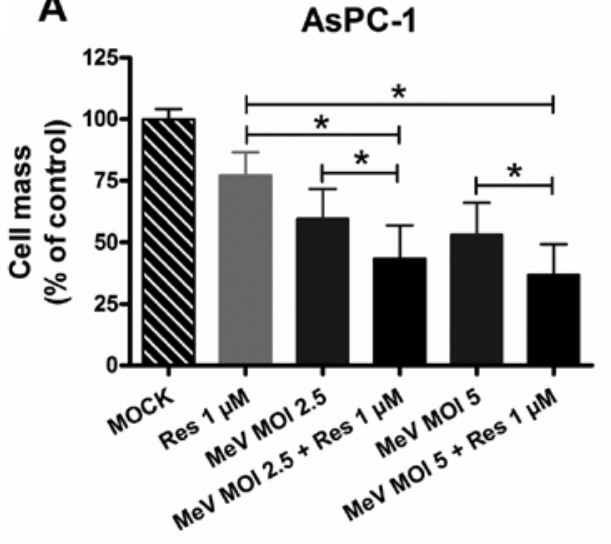

C

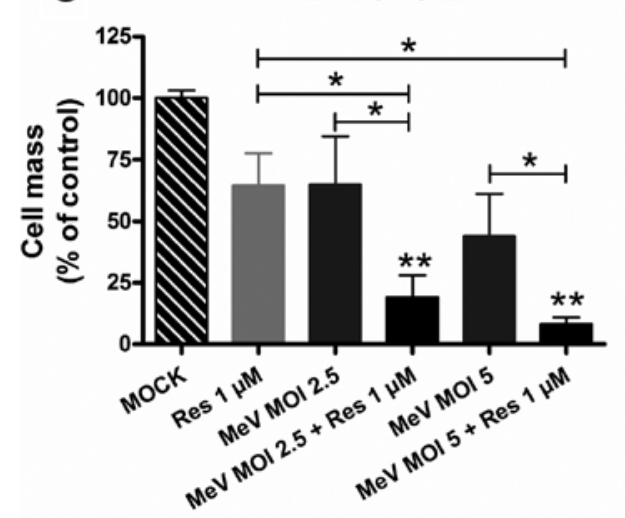

B

BxPC-3

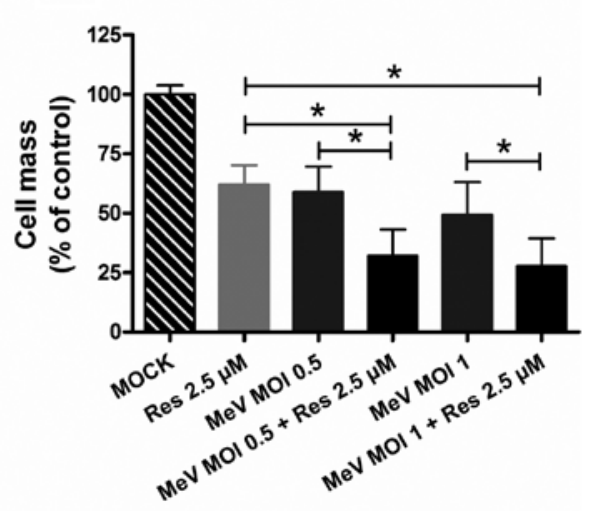

D

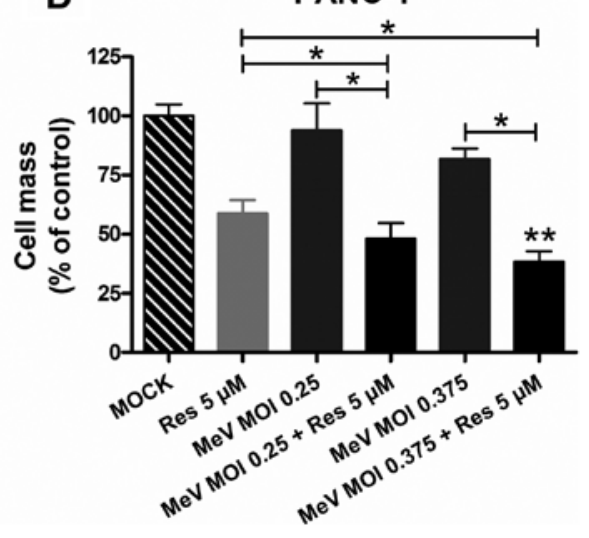

Figure 4. (A-D) Epi-virotherapeutic treatment is superior to any corresponding monotherapy. Tumor cells were infected with MeV-GFP (MeV) at indicated multiplicities of infection (50), being adjusted to the oncolytic susceptibility of the respective tumor cell line. At $3 \mathrm{~h}$ post infection (hpi), resminostat was added at the indicated concentrations. Remaining tumor cell masses were determined at 96 hpi using SRB viability assays. Means and SDs of three different experiments are shown. *P-value $<0.01$ of ANOVA on logarithms of tumor cell mass in \% of control, comparing epi-virotherapeutic treatment with mono-treatment of resminostat (Res) and MeV. ${ }^{* *} \mathrm{P}$-value $<0.01$ of interaction term in ANOVA verifying a more than additive (synergistic) effect.

oncolysis was PANC-1 (Fig. 3D), whereas AsPC-1 tumor cells (Fig. 3A) were found to be most resistant. Considering this, $>50 \%$ of AsPC-1 cells survived virus infections at a MOI of as high as 20 . In contrast, a tumor cell mass reduction of $50 \%$ was obtained by infecting PANC-1 cells at a MOI of as low as 1 . For further experiments, MOIs were adjusted in a tumor cell line-specific manner resulting in remaining tumor cell masses $75 \%$ at 96 hpi: MOIs of 2.5 and 5 for MIA PaCa-2 and AsPC-1; MOIs of 0.5 and 1 for BxPC-3, and MOIs of 0.25 and 0.375 for PANC-1.

Addressing the question whether there is cross-resistance between resminostat and MeV-GFP, a remarkable trend could be observed. Tumor cell lines, which had been identified to be more resistant toward resminostat exhibited a relatively strong sensitivity toward MeV-GFP-mediated oncolysis and vice versa. The largest difference in tumor cell susceptibility was obtained in experiments with the PANC-1 tumor cell line being most resistant against resminostat treatment, but most sensitive towards MeV-GFP-mediated oncolysis (Figs. 2D and 3D).

Enhanced tumor cell-killing by epi-virotherapeutic co-treatment. To further determine whether resminostat and oncolytic $\mathrm{MeV}$ operate beneficially when administered in combination, pancreatic cancer cells were initially infected with MeV-GFP; then, resminostat was added following the regular change of infection culture medium at 3 hpi (Fig. 4). Tumor cell line adjusted MOIs of MeV-GFP and concentrations of resminostat were used as determined prior in the monotherapy settings.

As a result, supplementation of oncolytic MeV-GFP by resminostat resulted in beneficial effects on rates of tumor cell mass reduction in all tested pancreatic cancer cell lines. With regard to MOIs of MeV-GFP and concentrations of resminostat employed in later experiments, the reduction in tumor cell mass could be amplified from 53 to $37 \%$ for AsPC-1 (MOI 5), from 60 to $32 \%$ for BxPC-3 (MOI 0.5), from 65 to $19 \%$ for MIA PaCa-2 (MOI 2.5), and from 93 to $48 \%$ for PANC-1 (MOI 0.25) (Fig. 4). Considering that HDACi per se induce a reduction in pancreatic cancer cell masses, the most striking benefit could be obtained in the treatment of MIA PaCa-2 cells, achieving a further $45 \%$ reduction in tumor cell mass (Fig. 4C, comparison of bars 2 and 6). Whereas both agents in monotherapy reduced tumor cell viability each by $35 \%$ in comparison to the mock control, the combination led to a tumor cell mass reduction of $>80 \%$ in comparison to the mock control (Fig. 4C, comparison of bars 1 and 6).

A statistical analysis was carried out to investigate whether an interaction between MeV-GFP and resminostat is verifiable that caused a more pronounced effect on tumor cell mass reduction than expected from a simple additive effect. 
A

AsPC-1

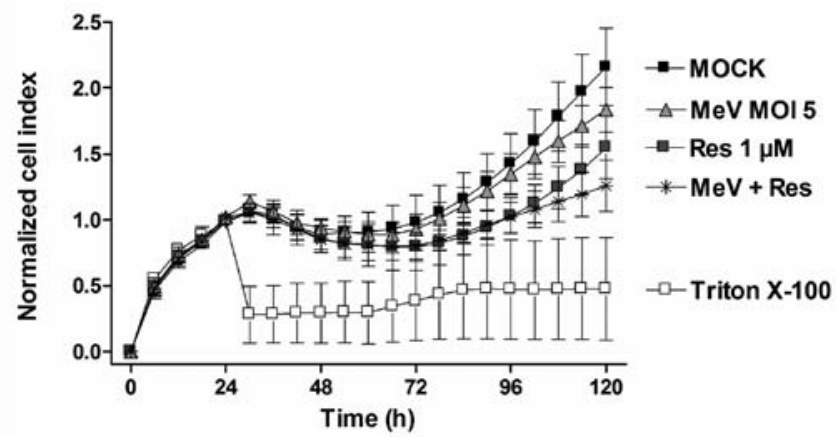

B

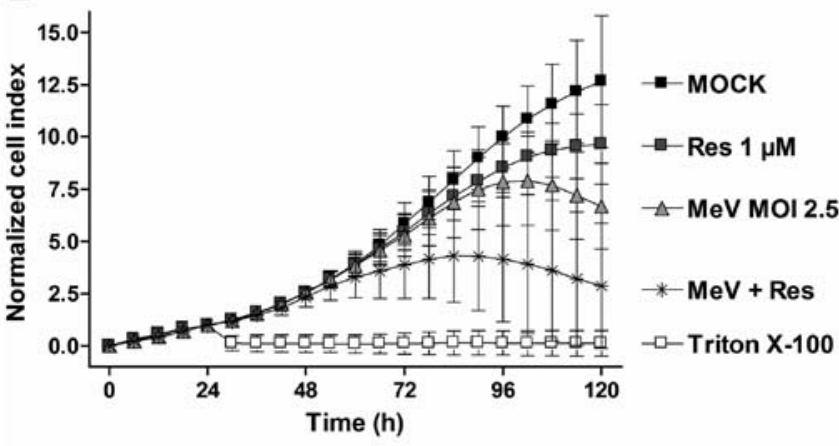

C

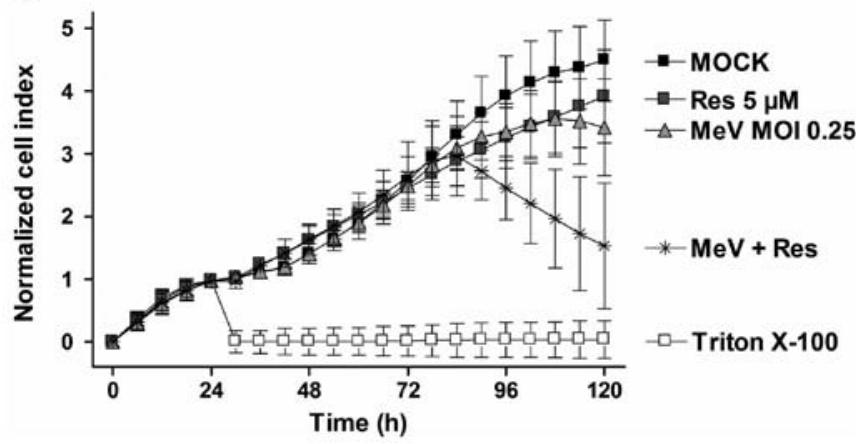

Figure 5. (A-D) Detailed analysis of pancreatic cancer cell viability ove $120 \mathrm{~h}$ of epi-virotherapeutic treatment. Beneficial effects of epi-virotherapeutic co-treatment were confirmed and specified by real-time proliferation monitoring providing tumor cell viability data over the entire treatment period of $120 \mathrm{~h}$. Following the initial tumor cell seeding (at hour 0), three of the four pancreatic cancer cells (AsPC-1, MIA PaCa-2 and PANC-1) were infected $21 \mathrm{~h}$ later with recombined measles virotherapeutics (MeV-GFP) at MOIs used in SRB combination-experiments or not treated (mock); then, at three hours post-infection, tumor cells were treated with the epitherapeutic compound resminostat (Res) at indicated concentrations. Treatment with Triton $\mathrm{X}-1001 \%$, inducing maximum tumor cell lysis, was used as a negative control. Cellular impedance was measured continuously using the xCELLigence SP system. Depicted are the data obtained in 6-h intervals. Cell index was normalized after $24 \mathrm{~h}$ when treatment had been accomplished (additional administration of resminostat or Triton X-100). Means and SDs of three different independent experiments are shown.

The interaction term in the ANOVA on the logarithms of tumor cell mass in \% of control confirmed a clear significant synergistic antitumor effect for the treatment of MIA $\mathrm{PaCa}-2$ cells (Fig. 4C) as compared to the cytotoxic effect that would be expected from an additive effect. With regard to the other pancreatic cancer cell lines, synergistic tumor cell killing could be significantly revealed in PANC-1 cells for only one of the two combinations ( $\mathrm{MeV}$ MOI 0.375 and $5 \mu \mathrm{M}$ resminostat; Fig. 4D); in contrast, no synergistic effects were found for AsPC-1 and BxPC-3 tumor cells (Fig. 4A and B), suggesting that the epi-virotherapeutic approach does not elicit synergistic effects in all pancreatic cancer cell entities, presumably as a result of tumor cell specific features.

To confirm our results from the SRB viability assays and to gain more precise information on the entire treatment time course, real-time pancreatic cancer cell proliferation was determined using the xCELLigence system (Fig. 5). The acquired data revealed that our epi-virotherapeutic treatment elicited beneficial effects on tumor cell viabilities in three out of the four tested pancreatic cancer cell lines (Fig. 5). Taken together, these findings underline that: i) our specific epi-virotherapeutic treatment is much more valuable for MIA PaCa-2 and PANC-1 tumor cells than for AsPC-1 cells (BxPC-3 tumor cells were not included in this specific testing) and ii) the mode of synergistic tumor cell killing is first observed at $72 \mathrm{hpi}$ in all tested pancreatic cancer cell lines (going along with $\mathrm{MeV}$-mediated oncolysis phenomena taking place at this time-point).

Absence of alterations in virus growth kinetics under continuous treatment with resminostat. To examine whether the resminostat-related enhancement of MeV-GFP-mediated oncolysis is based on an accelerated virus replication and spread, virus growth kinetics were analyzed for the four tested pancreatic cancer cell lines in presence and absence of resminostat at five different time-points (at 3, 24, 48, 72, and $96 \mathrm{hpi}$ ). For this purpose, tumor cells were infected with indicated MOIs and treated continuously with different concentrations of resminostat (Fig. 6). Comparing the virus growth curves of MeV-GFP monotreatment with those of co-treatment with resminostat, no relevant differences were obtained.

The highest virus titers were reached in PANC-1 and MIA PaCa-2 tumor cells (Fig. 6C and D), amounting to $10^{5} \mathrm{pfu} / \mathrm{ml}$ whereas in AsPC-1 and BxPC-3 titers of only $10^{4} \mathrm{pfu} / \mathrm{ml}$ were detected (Fig. 6A and B). In all tumor cell lines viral titers in supernatants were almost equal to those still bound inside tumor cells. Thus, there was no clear correlation between the susceptibility of the tumor cell lines toward measles vaccine virus-mediated oncolysis and virus titers.

At later time-points (at 72 and $96 \mathrm{hpi}$ ) viral titers were slightly lower in supernatants as well as in tumor cell lysates in the presence of resminostat. This may be due to a greater tumor cell mass reduction induced by the combination treatment at later time-points, so that fewer tumor cells were present in the cultures at these later time-points resulting in a significantly lower cellular capacity for production of viral progeny particles.

In conclusion, enhanced oncolytic effects by the combined treatment of MeV-GFP and resminostat were not found to be caused by an enhancement of viral replication by the HDACi.

Expression of surrogate parameter zinc finger protein 64 decreased in the course of resminostat treatment of pancreatic cancer cells. Decrease in the expression of zinc finger protein 64 (zfp64) has been revealed to be a good surrogate parameter for the pharmacological activity of resminostat. 
A

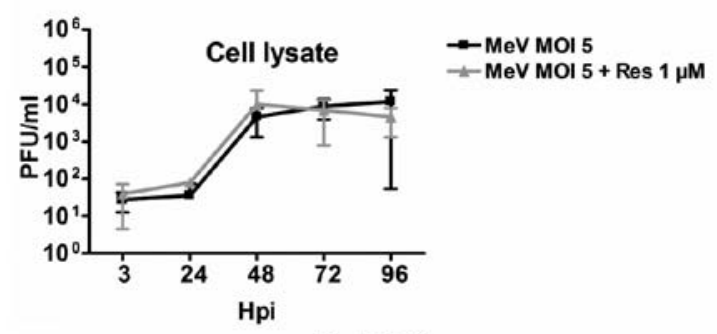

B

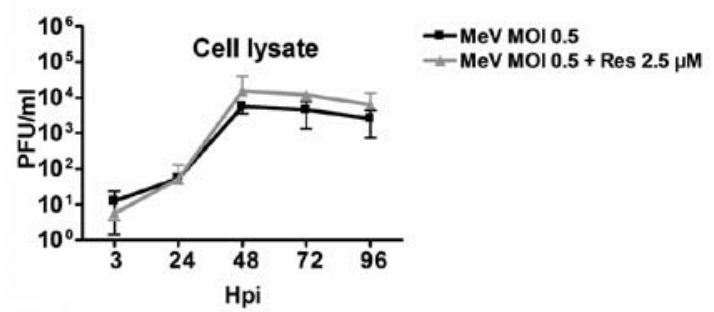

C

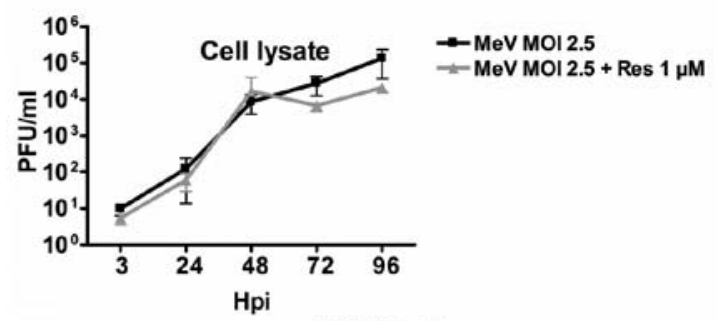

PANC-1

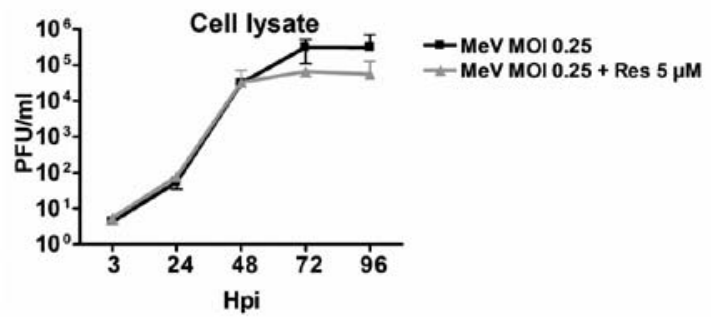

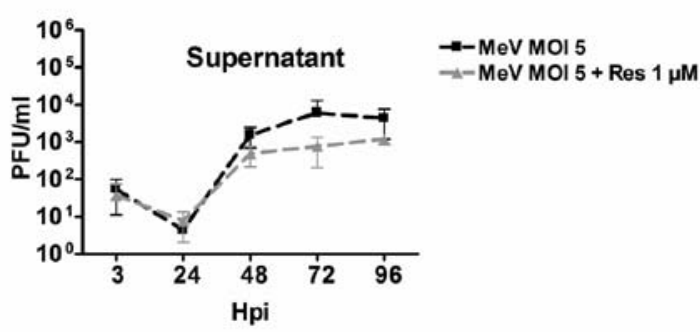
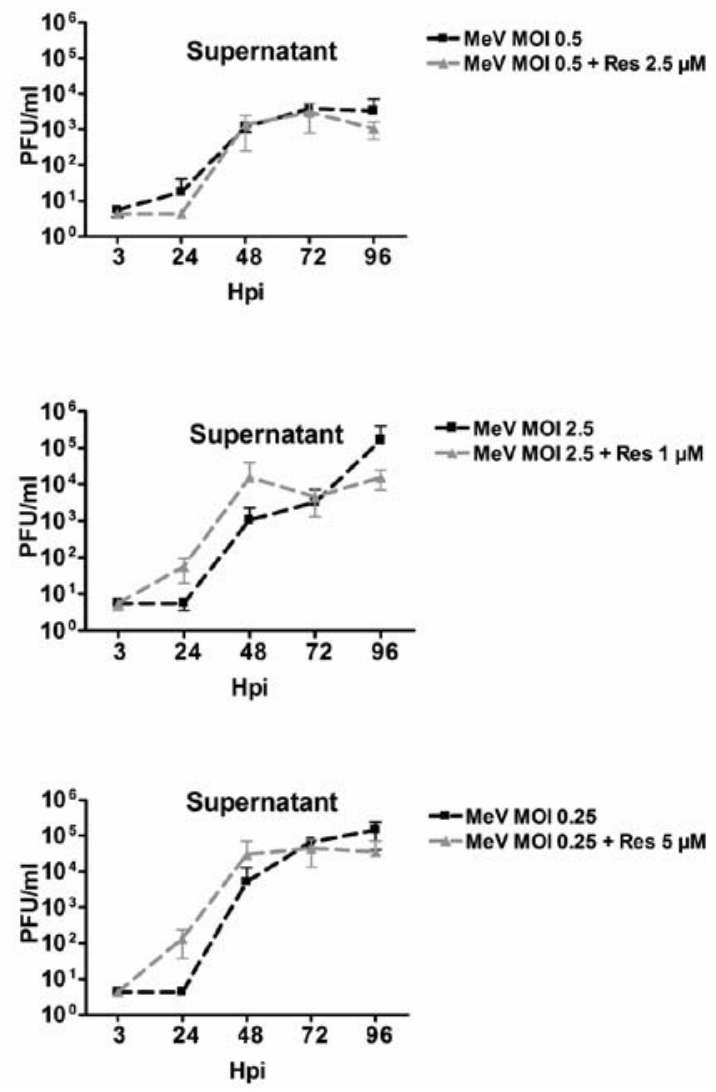

Figure 6. (A-D) Resminostat co-treatment did not alter MeV-GFP growth kinetics. Virus growth curves of well characterized pancreatic cancer cell lines did not exhibit significant differences of measles virotherapeutic replication when being determined in absence or in presence of the epigenetic compound resminostat. Tumor cells were co-treated with MeV-GFP (MeV) and resminostat (Res) at stated multiplicities of infection (MOIs) and concentrations of the epigenetic compound $(\mu \mathrm{M})$. Samples were taken at 3, 24, 48, 72 and $96 \mathrm{~h}$ post-infection (hpi). Tumor cell lysates (curves to the left, solid lines) provide information on viral particles being found in intact tumor cells, whereas supernatant samples (curves to the right, dotted lines) reflect the release of newly generated infectious MeV-GFP particles from tumor cells. Results were obtained by virus titration on Vero cells. Displayed are means and SDs of three independent experiments. pfu, plaque forming unit; hpi, hours post-infection.

Therefore, we examined mRNA expression of zfp64 after monotreatment with either resminostat or MeV-GFP and after combination treatment (resminostat plus MeV-GFP) using the same resminostat concentrations and MOIs as in all prior experiments (Fig. 7). In the presence of resminostat, zfp64 expression was found to be downregulated in each tumor cell line as early as after five hours of treatment initiation. Under epi-virotherapeutic co-treatment with resminostat and MeV-GFP, we still observed a lower expression of zfp64 as compared to the mock-treated control (with AsPC-1 tumor cells showing an even lower expression under co-treatment as compared to resminostat treatment alone; Fig. 7A). In contrast, different expression patterns of zfp64 were found when tumor cells had only been infected with MeV-GFP; in these cases, zfp64 was only downregulated in BxPC-3 and MIA PaCa-2 tumor cells (Fig. 7B and C), but there was no detectable regulation in AsPC-1 and PANC-1 tumor cells (Fig. 7A and D).

In conclusion, our experiments provide evidence that the pharmacodynamic function of resminostat did not seem to be impaired in MeV-GFP-infected pancreatic cancer cell lines.

Resminostat did not impair activation of IFN signaling. In most studies investigating epi-virotherapeutic approaches so far, damping of the anti-viral response by HDACi was highlighted as a potential explanation for underlying synergistic antitumoral effects of this combined treatment approach. 
A

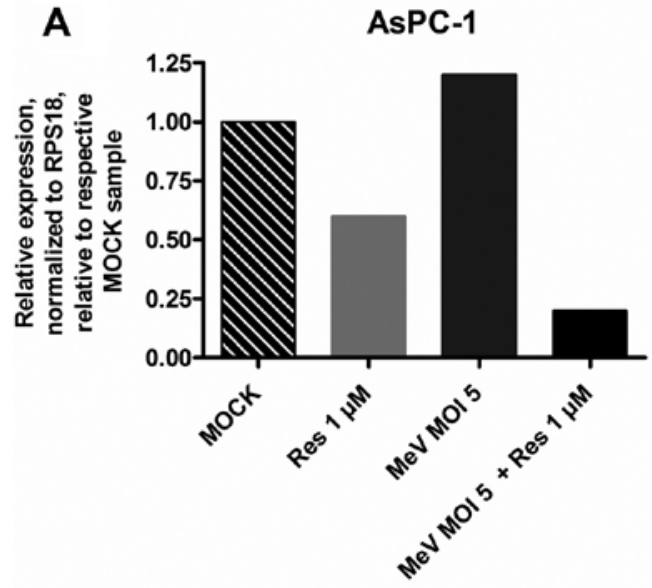

C

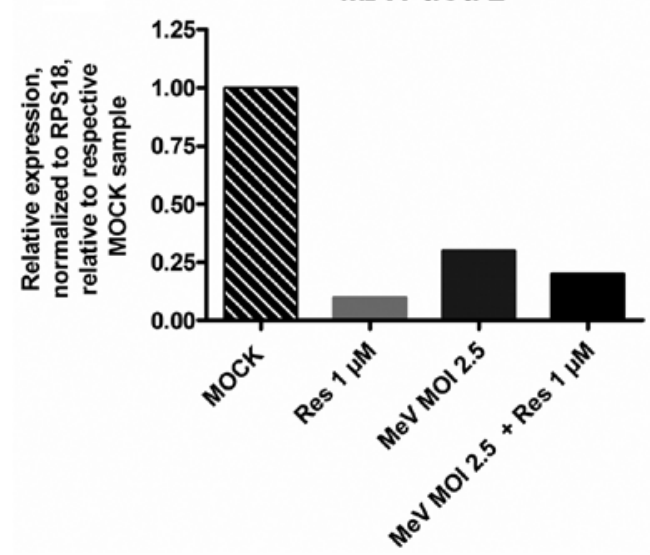

B

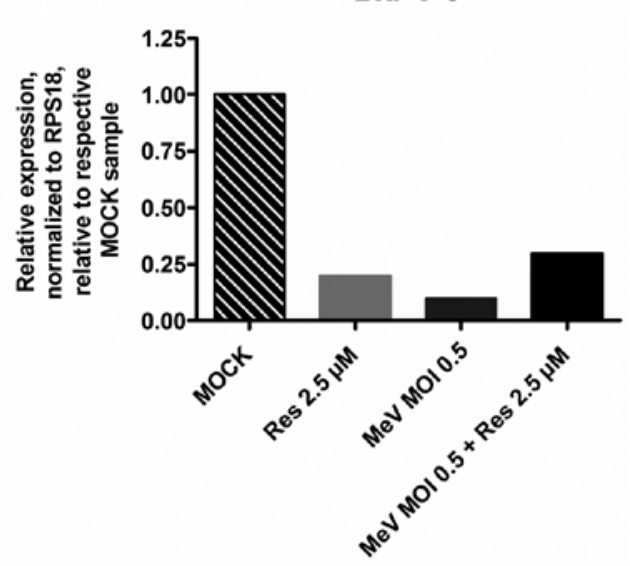

D

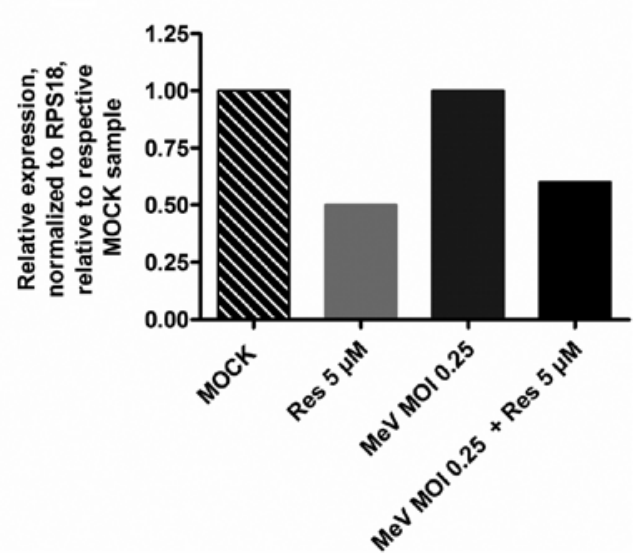

Figure 7. (A-D) Analysis of the resminostat pharmacodynamic function in MeV-GFP-infected pancreatic cancer cells. Unimpairment of the resminostat (Res) pharmacodynamic function in pancreatic cancer cells being infected with recombined measles virotherapeutics (MeV-GFP) was deduced from the decrease in expression of zinc-finger protein 64 (zfp64) after $5 \mathrm{~h}$ of epigenetic treatment. Tumor cells were infected with MeV-GFP at stated MOIs and co-treated with indicated concentrations of resminostat starting at $3 \mathrm{~h}$ post-infection. RNA samples were obtained after $5 \mathrm{~h}$ of treatment. Expression levels of zfp64, representing a well-defined surrogate parameter for the epigenetic impact of resminostat, were determined using RT-qPCR. Values were normalized to the housekeeping gene RPS 18 (ribosomal protein S18), and relative expression is displayed compared to corresponding control samples (mock; no infection with MeV-GFP and no treatment with resminostat). Data of a representative experiment are shown. MeV + Res, co-treatment with measles virus MeV-GFP and resminostat with concentrations and MOIs as used in the respective mono-treatment experiments.

Accordingly, we were interested in the functionality of IFN-signaling of pancreatic cancer cells in the presence and absence of resminostat during infections with MeV-GFP.

Many tumor cells are known to exhibit defects in IFN signaling and are therefore considered to be susceptible to $\mathrm{OV}$-mediated oncolysis (53). In this context, we first examined whether pancreatic cancer cells have the ability of initiating an IFN response in the course of an infection by MeV. For this purpose, pancreatic cancer cells were infected with MeV-GFP at standard MOIs (0.25 for PANC-1, 0.5 for BxPC-3, 2.5 for MIA PaCa-2, and 5 for AsPC-1, respectively). Furthermore, control samples were generated by stimulating cells with IFN- $\beta$ for $24 \mathrm{~h}$. Samples were taken at 24, 48, 72, and $96 \mathrm{hpi}$. In AsPC-1, BxPC-3, and PANC-1 tumor cells phosphorylation of STAT1 and expression of IFN-induced protein with tetratricopeptide repeats 1 (IFIT1) were observed at the latest at $72 \mathrm{hpi}$ indicating an unaltered activation of IFN signaling (data not shown). In contrast, in MIA PaCa-2 cells neither phosphorylation of STAT1 nor expression of IFIT1 was detected after MeV-GFP infection being indicative of a severe defect in IFN signaling in this distinct tumor cell line (Fig. 8).

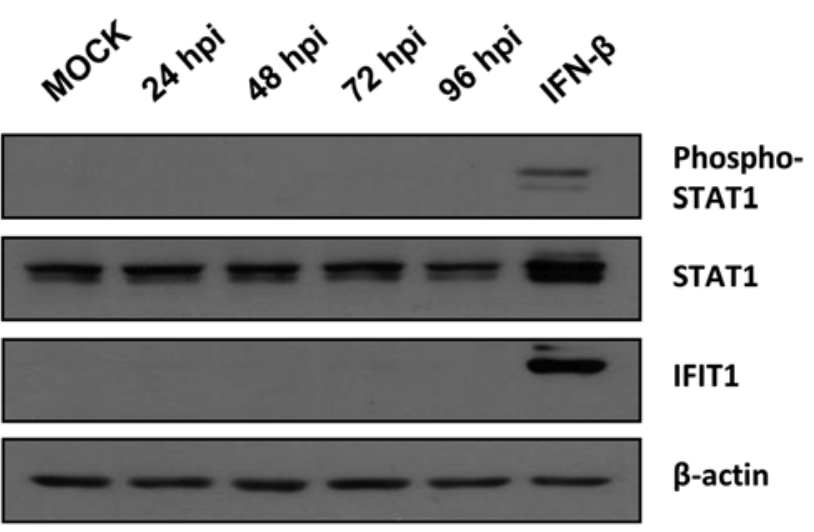

Figure 8. MeV-GFP did not induce IFN signaling in MIA PaCa-2 cells. Tumor cells were either infected with MeV-GFP (MOI 2.5) or treated without infection (mock); then, samples were taken at 24, 48, 72 and $96 \mathrm{~h}$ post-infection (hpi) and analyzed by immunoblotting; tumor cells stimulated with interferon- $\beta$ (IFN- $\beta$ ) were used as positive controls. Potential activation of IFN signaling by MeV-GFP was deduced from phosphorylation of STAT1 (phospho-STAT1) and expression of interferon-induced protein with tetratricopeptide repeats 1 (IFIT1). $\beta$-actin was used as a loading control. 

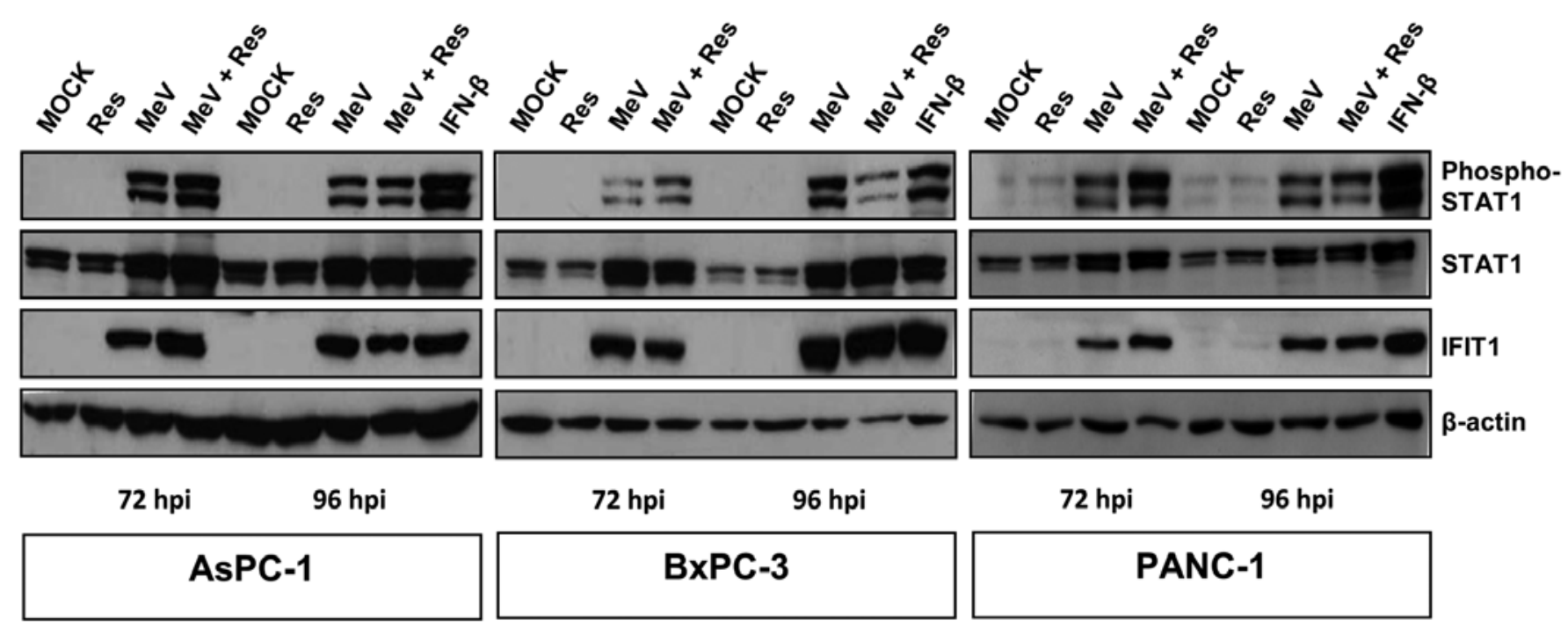

Figure 9. Resminostat does not impair MeV-induced activation of IFN signaling. AsPC-1, BxPC-3 and PANC-1 cells were mock-treated (mock), treated with resminostat (Res) or/and MeV-GFP (MeV) or not treated at all (mock). Stimulation with IFN- $\beta$ for $24 \mathrm{~h}$ (IFN- $\beta$ ) served as a positive control. MeV-induced activation of IFN-signaling was revealed by phosphorylation of STAT1 (phospho-STAT1) and expression of IFIT1, being detected by immunoblotting. $\beta$-actin was used as a loading control.

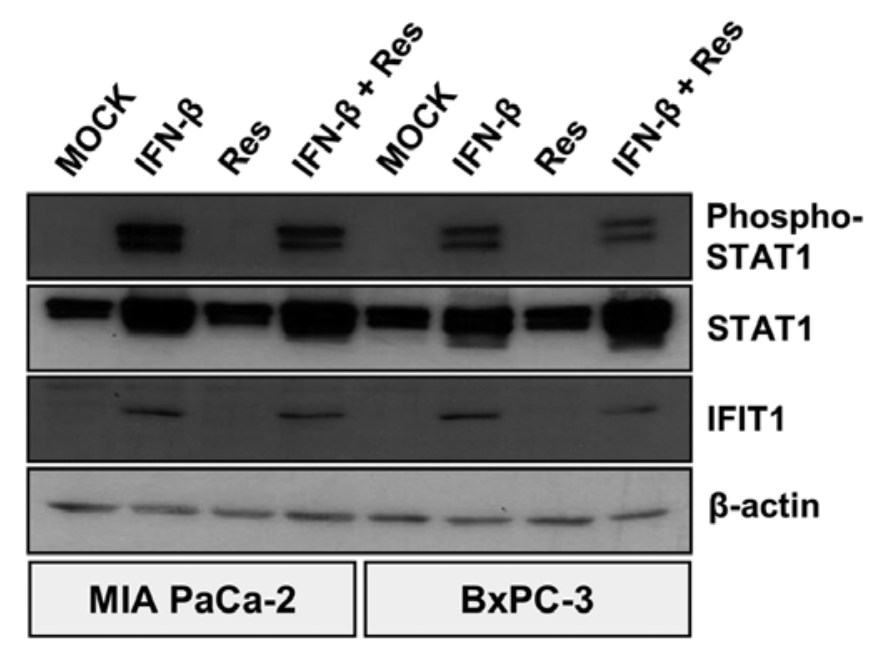

Figure 10. Resminostat does not impair IFN signaling in MIA PaCa-2 cells being exogenously stimulated by IFN. MIA PaCa- 2 and BxPC-3 cells were treated with IFN- $\beta$ and/or resminostat (Res) for $24 \mathrm{~h}$ or not treated at all (mock). Potential impairment of IFN signaling by resminostat was deduced from phosphorylation of STAT1 (phospho-STAT1) and expression of interferon-induced protein with tetratricopeptide repeats 1 (IFIT1). $\beta$-actin was used as a loading control.

We then investigated the impact of resminostat on MeV-GFP-induced activation of IFN signaling in AsPC-1, BxPC-3, and PANC-1 cells. As a result, resminostat monotreatment did neither result in phosphorylation of STAT1 nor in expression of IFIT1. However, both MeV-GFP infection alone as well as the epi-virotherapeutic combination resminostat plus MeV-GFP were found to activate IFN signaling at both 72 and $96 \mathrm{hpi}$, indicated by phosphorylation of STAT1 and expression of IFIT1 (Fig. 9). As MIA PaCa-2 cells did not initiate IFN signaling after MeV-GFP infection, we stimulated these tumor cells with IFN- $\beta$ (please note: BxPC-3 cells were used as a control in this experiment). Some of these were additionally treated with resminostat. As a result, IFN- $\beta$ treatment was found to induce IFN signaling; but similar to all prior results, resminostat was unable to inhibit phosphorylation of STAT1 and expression of IFIT1 (Fig. 10). These results clearly imply that resminostat does not impair the IFN response of pancreatic cancer cells that had been initiated by infection with MeV-GFP. Consequently, resminostat does not elicit synergistic effects due to an impairment of the anti-viral response.

\section{Discussion}

Oncolytic viruses have recently made a major move toward their full establishment in clinical practice by approval of Imlygic ${ }^{\circledR}$ both by the American Food and Drug Administration (FDA) and by the European Medicines Agency (EMA) (7).

In our study, an epi-virotherapeutic approach was pursued, augmenting oncolytic $\mathrm{MeV}$ with the oral HDACi resminostat. Both agents already have been evaluated independently as well as recently in combination for the treatment of different solid tumors with encouraging results $(1,14,24,45,54-57)$. Here, we tested a series of four human pancreatic cancer cell lines: i) for their sensitivity to both agents in monotreatment and subsequently, ii) toward the effect of epi-virotherapeutic co-treatment.

At the outset, monotreatment experiments revealed that both agents, oncolytic MeV-GFP as well as resminostat, caused dose- and time-dependent tumor cell killing in all tested human pancreatic cancer cell lines. Strikingly, the cytotoxic effect of resminostat on a specific cancer cell line could not be predicted from the results obtained in OV cytotoxicity assays and vice versa. This is most clearly visible when comparing the virotherapeutic with the epigenetic results obtained with PANC-1 cells emphasizing that there are no cross-resistances between $\mathrm{OV}$ and other cytotoxic drugs such as HDACi. 
Subsequently, cooperative effects were evaluated by performing SRB cell viability assays and afterwards confirmed utilizing the xCELLigence system. The results showed that the epi-virotherapeutic approach elicited beneficial cytotoxic effects in all four pancreatic cancer cell lines. Regarding MIA $\mathrm{PaCa}-2$ tumor cells, considerable synergistic results were observed: virus-mediated reduction in the tumor cell masses was found to be improved in the presence of resminostat from 35 to $81 \%$ (at MOI 2.5) as well as from 55 to $92 \%$ (at MOI 5) (Fig. 4). Similarly, epi-virotherapeutic treatment of the other three cancer cell lines exhibited stronger effects than obtained in monotreatment. In further experiments we found that virus growth curves revealed no significant differences in the presence or absence of resminostat, suggesting that resminostat neither facilitated virus entry nor enhanced virus replication.

With regard to studies that have already investigated the therapeutic potential of epi-virotherapeutic treatment of different tumor entities, the most frequently examined and highlighted molecular mechanism of synergism is the ability of HDACi to impair the anti-viral immune response of host tumor cells, thereby facilitating virus replication and spread. Many underlying mechanisms have been revealed, describing involvement of HDAC activity in almost each step of IFN signaling. Virus infection leads to phosphorylation of IFN-regulatory factors (IRFs), homo- or heterodimerization and translocation into the nucleus where IFN- $\beta$ expression is induced (58). Trichostatin A (TSA) was shown to prevent proper IRF-3 function, thereby hindering cells to produce IFN- $\beta$ (25). Downstream signaling of the IFN- $\beta$ receptor likewise requires HDAC activity, enabling proper receptor activation, STAT dimerization, and IRF-9 function as well as the formation of the IFN-stimulated gene factor-3 (ISGF3) (26-28). Also, HDAC are involved in the expression of IFN-stimulated-genes (ISGs) (29). Accordingly, HDAC inhibitors were proven to impair the expression of ISGs when tumor cells were coincidently infected with oncolytic viruses $(30,36,59)$. Due to these findings, the enhanced oncolytic effect was retrospectively assigned to the interference with IFN signaling.

In contrast to these observations, the present epivirotherapeutic approach did not modulate IFN signaling as indicated by an unaltered phosphorylation of STAT1 and expression of the ISG IFIT1 in any of the tested pancreatic cancer cell lines. Moreover, no obvious alteration in virus growth kinetics could be observed. For these reasons, our experiments do not support the prevailing opinion of HDACi damping the IFN-response thus enhancing OV-mediated oncolysis. In respect of implementing our epi-virotherapeutic approach into clinical practice, it is potentially not preferable that type I IFN production is impaired. Since especially IFN- $\alpha$ and IFN- $\beta$ are essential cytokines that attract and prime cytotoxic and $\mathrm{T}$ helper cells by causing expression of important receptors on cancer cells (such as MHC I), type I IFN secretion from tumor sites might amplify an antitumor immune response $(60,61)$.

Other studies having examined the potential of HDACi to enhance different virotherapeutics obtained similar findings. After having infected different infection-resistant cancer cells with vaccinia virus (VV) that had retained their B18R gene, functioning as an IFN antagonist, the HDACi TSA was still capable of amplifying OV-mediated oncolysis, suggesting that its antitumor effect was not based on an immunosuppressive function (19). In our study, MIA PaCa-2 was the only pancreatic cancer cell line which did not exhibit an activation of the IFN signaling pathway after $\mathrm{MeV}$ infection. Despite this lack of establishing a proper anti-viral state, it was not the most susceptible cell line to MeV-mediated oncolysis and more noteworthy, epi-virotherapeutic treatment showed the most pronounced effect in this cell line, stressing that HDACi seem to enhance virus-mediated oncolysis by eliciting other effects than damping the IFN response. This raises the question which additional mechanisms could explain the enhancement of virus-mediated cell death by epi-virotherapeutic co-treatment.

Explanations, amongst others, were provided by Liu et al (31). Using an epi-virotherapeutic approach consisting of oncolytic herpes-simplex-virus (HSV) and TSA in a panel of tumor and normal quiescent cells, they obtained beneficial cytoreductive effects compared to monotreatment. These effects could be attributed neither to the dosing schedule nor to enhanced infectivity or virus replication. The authors rather ascribed the results to a decrease in expression of cyclin D1, mediating cell cycle arrest, and VEGF, reinforcing the hypothesis of vascular shutdown induced by OV (5).

Beyond the above, further replication-independent mechanisms have been illustrated, highlighting the impact of HDACi on cell signaling. Thus, HDACi cause hyperacetylation of $\mathrm{NF}-\kappa \mathrm{B}$, thereby increasing its nuclear retention and DNA binding capacity. Due to its promotion of HSV gene expression, this HDACi-mediated effect elicited synergistic tumor killing in oral squamous cell carcinoma (SCC) cells (62). Furthermore, combined treatment was shown to increase the expression of p21 which mediates cell cycle arrest, consequently slowing down tumor progression and resulting in the induction of tumor cell apoptosis.

Recently, Shulak et al found a mechanism explaining $\mathrm{NF}-\kappa \mathrm{B}$ activity accompanied by an enhanced OV-mediated oncolysis. They pointed out that hyperacetylation and nuclear retention of $N F-\kappa B$ induced the expression of several autophagy-related genes. They argued that the induction of autophagy led to an impairment of IFN signaling but also to vesicular stomatitis virus (VSV)-mediated apoptosis in prostate cancer cells (36). Autophagy is a process that is per se frequently enhanced in tumor cells since it serves as a stress response to oxidative stress, lack of nutrients, and hypoxia as it is commonly present in the microenvironment of solid tumors (63). Interestingly, pancreatic cancer cells even require this catabolic process in order to prevent accumulation of ROS, thereby contributing to tumor growth as well as establishing the basis for drug resistance $(64,65)$. Despite these pro-survival aspects, some viruses are notably capable of exploiting the autophagic machinery for the purpose of efficient replication (38). Attenuated $\mathrm{MeV}$ derived from the Edmonston strain actually induce and require autophagy for efficient replication (37). Since hydroxamic acid based HDACi equally increase autophagic activity (66), it is tempting to speculate that the effect elicited by resminostat in combination with oncolytic $\mathrm{MeV}$ is caused by an enhanced self-digestion and subsequently enhanced tumor cell death.

Physiologically, cell signaling often requires protein modifications such as phosphorylation or acetylation but beyond targeting cell proteins, even pathogenic proteins can 
serve as substrates for those modifications, resulting either in enhanced or impaired activity. In this context, it was revealed that a portion of the NS-1 protein, representing the major pathogenic and most important protein for replication of the rat parvovirus $\mathrm{H}-1 \mathrm{PV}$, gets acetylated during virus infection (67). Noteworthy, treatment with VPA caused hyperacetylation of NS-1 resulting in an accumulation of ROS and an enhanced transcriptional activity. Ultimately, DNA damage in cancer cells was observed consequently inducing apoptosis. Those findings were confirmed later in vivo, resulting in complete disappearance of implanted tumors in mice that had undergone co-treatment with H-1PV and VPA (18). Likewise, HDACirelated hyperacetylation of microtubules accelerated nuclear translocation of oncolytic HSV-genomes, thereby enhancing the antitumor effect in glioma stem-like cells (39).

In conclusion, our results provide evidence that the epivirotherapeutic combination of oncolytic $\mathrm{MeV}$ and the HDACi resminostat constitutes a beneficial option in the treatment of advanced pancreatic ductal adenocarcinoma. We revealed an augmentation of $\mathrm{MeV}$-mediated oncolysis by resminostat. Treatment of MIA PaCa- 2 cells resulted even in a synergistic enhancement of the tumor-killing potential when compared to the monotherapies. Molecular mechanisms underlying the synergistic effects and the potential of our epi-virotherapeutic approach in vivo have to be elucidated in animal models in the future.

\section{Acknowledgements}

For the statistical analysis the methodical advice from the Institute of Clinical Epidemiology and Applied Biometrics of the University Hospital Tuebingen were utilized. We wish to thank Professor Martin Eichner for his excellent support, and we further wish to thank Hannes Schramm (University Hospital Tuebingen) who helped us with imaging and the augmentation of oncolytic viruses by histone deacetylase inhibitors. Dr Tanja Wulff is an employee of 4SC AG. T.P.E. was funded by the intramural IZKF-scholarship of the Faculty of Medicine, University of Tuebingen. S.B. was supported by the German Childhood Cancer Foundation (DKS) and M.B. by grants of the European Foundation for Alcohol Research (ERAB). We further acknowledge the support by the German Research Foundation (DFG) and the Open Access Publishing Fund of the Eberhard Karls University of Tuebingen.

\section{References}

1. Russell SJ, Peng KW and Bell JC: Oncolytic virotherapy. Nat Biotechnol 30: 658-670, 2012.

2. Hammill AM, Conner J and Cripe TP: Oncolytic virotherapy reaches adolescence. Pediatr Blood Cancer 55: 1253-1263 2010.

3. Bourke MG, Salwa S, Harrington KJ, Kucharczyk MJ, Forde PF, de Kruijf M, Soden D, Tangney M, Collins JK and O'Sullivan GC: The emerging role of viruses in the treatment of solid tumours. Cancer Treat Rev 37: 618-632, 2011.

4. Smith TT, Roth JC, Friedman GK and Gillespie GY: Oncolytic viral therapy: Targeting cancer stem cells. Oncolytic Virother 2014: 21-33, 2014.

5. Breitbach CJ, De Silva NS, Falls TJ, Aladl U, Evgin L, Paterson J, Sun YY, Roy DG, Rintoul JL, Daneshmand M, et al: Targeting tumor vasculature with an oncolytic virus. Mol Ther 19: 886-894, 2011
6. Andtbacka RH, Kaufman HL, Collichio F, Amatruda T, Senzer N, Chesney J, Delman KA, Spitler LE, Puzanov I, Agarwala SS, et al: Talimogene laherparepvec improves durable response rate in patients with advanced melanoma. J Clin Oncol 33: 2780-2788, 2015.

7. Ledford $\mathrm{H}$ : Cancer-fighting viruses win approval. Nature 526: 622-623, 2015.

8. Russell SJ, Federspiel MJ, Peng KW, Tong C, Dingli D, Morice WG, Lowe V, O'Connor MK, Kyle RA, Leung N, et al: Remission of disseminated cancer after systemic oncolytic virotherapy. Mayo Clin Proc 89: 926-933, 2014.

9. Chiocca EA: The host response to cancer virotherapy. Curr Opin Mol Ther 10: 38-45, 2008.

10. Kim M, Zinn KR, Barnett BG, Sumerel LA, Krasnykh V, Curiel DT and Douglas JT: The therapeutic efficacy of adenoviral vectors for cancer gene therapy is limited by a low level of primary adenovirus receptors on tumour cells. Eur J Cancer 38: 1917-1926, 2002.

11. Berchtold S, Lampe J, Weiland T, Smirnow I, Schleicher S, Handgretinger R, Kopp HG, Reiser J, Stubenrauch F, Mayer N, et al: Innate immune defense defines susceptibility of sarcoma cells to measles vaccine virus-based oncolysis. J Virol 87: 3484-3501, 2013

12. Escobar-Zarate D, Liu YP, Suksanpaisan L, Russell SJ and Peng KW: Overcoming cancer cell resistance to VSV oncolysis with JAK1/2 inhibitors. Cancer Gene Ther 20: 582-589, 2013.

13. Noll M, Berchtold S, Lampe J, Malek NP, Bitzer M and Lauer UM: Primary resistance phenomena to oncolytic measles vaccine viruses. Int J Oncol 43: 103-112, 2013.

14. Nguyen TL, Wilson MG and Hiscott J: Oncolytic viruses and histone deacetylase inhibitors - a multi-pronged strategy to target tumor cells. Cytokine Growth Factor Rev 21: 153-159, 2010.

15. Nakashima H, Nguyen $T$ and Chiocca EA: Combining HDAC inhibitors with oncolytic virotherapy for cancer therapy. Dovepress 2015: 183-191, 2015.

16. Khan $\mathrm{O}$ and La Thangue NB: HDAC inhibitors in cancer biology: Emerging mechanisms and clinical applications. Immunol Cell Biol 90: 85-94, 2012

17. Bolden JE, Peart MJ and Johnstone RW: Anticancer activities of histone deacetylase inhibitors. Nat Rev Drug Discov 5: 769-784, 2006.

18. Li J, Bonifati S, Hristov G, Marttila T, Valmary-Degano S, Stanzel S, Schnölzer M, Mougin C, Aprahamian M, Grekova SP, et al: Synergistic combination of valproic acid and oncolytic parvovirus $\mathrm{H}-1 \mathrm{PV}$ as a potential therapy against cervical and pancreatic carcinomas. EMBO Mol Med 5: 1537-1555, 2013.

19. MacTavish H, Diallo JS, Huang B, Stanford M, Le Boeuf F, De Silva N, Cox J, Simmons JG, Guimond T, Falls T, et al: Enhancement of vaccinia virus based oncolysis with histone deacetylase inhibitors. PLoS One 5: e14462, 2010.

20. White MC and Frampton AR Jr: The histone deacetylase inhibitor valproic acid enhances equine herpesvirus type 1 (EHV-1)-mediated oncolysis of human glioma cells. Cancer Gene Ther 20: 88-93, 2013.

21. Bridle BW, Chen L, Lemay CG, Diallo JS, Pol J, Nguyen A, Capretta A, He R, Bramson JL, Bell JC, et al: HDAC inhibition suppresses primary immune responses, enhances secondary immune responses, and abrogates autoimmunity during tumor immunotherapy. Mol Ther 21: 887-894, 2013.

22. Cody JJ, Markert JM and Hurst DR: Histone deacetylase inhibitors improve the replication of oncolytic herpes simplex virus in breast cancer cells. PLoS One 9: e92919, 2014.

23. Alvarez-Breckenridge CA, Yu J, Price R, Wei M, Wang Y, Nowicki MO, Ha YP, Bergin S, Hwang C, Fernandez SA, et al: The histone deacetylase inhibitor valproic acid lessens NK cell action against oncolytic virus-infected glioblastoma cells by inhibition of STAT5/T-BET signaling and generation of gamma interferon. J Virol 86: 4566-4577, 2012.

24. Ruf B, Berchtold S, Venturelli S, Burkard M, Smirnow I, Prenzel T, Henning SW and Lauer UM: Combination of the oral histone deacetylase inhibitor resminostat with oncolytic measles vaccine virus as a new option for epi-virotherapeutic treatment of hepatocellular carcinoma. Mol Ther Oncolytics 2: 15019, 2015.

25. Nusinzon I and Horvath CM: Positive and negative regulation of the innate antiviral response and beta interferon gene expression by deacetylation. Mol Cell Biol 26: 3106-3113, 2006.

26. Génin $P$, Morin $P$ and Civas A: Impairment of interferon-induced IRF-7 gene expression due to inhibition of ISGF3 formation by trichostatin A. J Virol 77: 7113-7119, 2003. 
27. Tang X, Gao JS, Guan YJ, McLane KE, Yuan ZL, Ramratnam B and Chin YE: Acetylation-dependent signal transduction for type I interferon receptor. Cell 131: 93-105, 2007.

28. Yuan ZL, Guan YJ, Chatterjee D and Chin YE: Stat3 dimerization regulated by reversible acetylation of a single lysine residue. Science 307: 269-273, 2005.

29. Chang HM, Paulson M, Holko M, Rice CM, Williams BR, Marié I and Levy DE: Induction of interferon-stimulated gene expression and antiviral responses require protein deacetylase activity. Proc Natl Acad Sci USA 101: 9578-9583, 2004

30. Otsuki A, Patel A, Kasai K, Suzuki M, Kurozumi K, Chiocca EA and Saeki Y: Histone deacetylase inhibitors augment antitumor efficacy of herpes-based oncolytic viruses. Mol Ther 16 : 1546-1555, 2008.

31. Liu TC, Castelo-Branco P, Rabkin SD and Martuza RL: Trichostatin A and oncolytic HSV combination therapy shows enhanced antitumoral and antiangiogenic effects. Mol Ther 16: 1041-1047, 2008.

32. Wunder T, Schmid K, Wicklein D, Groitl P, Dobner T, Lange T, Anders M and Schumacher U: Expression of the coxsackie adenovirus receptor in neuroendocrine lung cancers and its implications for oncolytic adenoviral infection. Cancer Gene Ther 20: 25-32, 2013.

33. Kasman L, Onicescu G and Voelkel-Johnson C: Histone deacetylase inhibitors restore cell surface expression of the coxsackie adenovirus receptor and enhance CMV promoter activity in castration-resistant prostate cancer cells. Prostate Cancer 2012: 137163, 2012.

34. Stiff A, Caserta E, Sborov DW, Nuovo GJ, Mo X, Schlotter SY, Canella A, Smith E, Badway J, Old M, et al: Histone deacetylase inhibitors enhance the therapeutic potential of reovirus in multiple myeloma. Mol Cancer Ther 15: 830-841, 2016.

35. Meng S, Xu J, Wu Y and Ding C: Targeting autophagy to enhance oncolytic virus-based cancer therapy. Expert Opin Biol Ther 13: 863-873, 2013

36. Shulak L, Beljanski V, Chiang C, Dutta SM, Van Grevenynghe J, Belgnaoui SM, Nguyên TL, Di Lenardo T, Semmes OJ, Lin R, et al: Histone deacetylase inhibitors potentiate vesicular stomatitis virus oncolysis in prostate cancer cells by modulating NF-кB-dependent autophagy. J Virol 88: 2927-2940, 2014.

37. Richetta C, Grégoire IP, Verlhac P, Azocar O, Baguet J Flacher M, Tangy F, Rabourdin-Combe C and Faure M: Sustained autophagy contributes to measles virus infectivity. PLoS Pathog 9: e1003599, 2013

38. Dreux M and Chisari FV: Viruses and the autophagy machinery. Cell Cycle 9: 1295-1307, 2010.

39. Nakashima H, Kaufmann JK, Wang PY, Nguyen T, Speranza MC, Kasai K, Okemoto K, Otsuki A, Nakano I, Fernandez S, et al: Histone deacetylase 6 inhibition enhances oncolytic viral replication in glioma. J Clin Invest 125: 4269-4280, 2015.

40. Guillerme JB, Gregoire M, Tangy F and Fonteneau JF: Antitumor virotherapy by attenuated measles virus (MV). Biology (Basel) 2: 587-602, 2013.

41. Hutzen BRC and Studebaker AW: Advances in the design and development of oncolytic measles viruses. Dovepress 4: 109-118, 2015.

42. Bitzer M, Horger M, Giannini EG, Ganten TM, Wörns MA, Siveke JT, Dollinger mM, Gerken G, Scheulen ME, Wege H, et al: Resminostat plus sorafenib as second-line therapy of advanced hepatocellular carcinoma - The SHELTER Study. J Hepatol 65: 280-288, 2016.

43. Russell SJ and Peng KW: Measles virus for cancer therapy. Curr Top Microbiol Immunol 330: 213-241, 2009.

44. Hidalgo M: Pancreatic cancer. N Engl J Med 362: 1605-1617, 2010.

45. Brunetto AT, Ang JE, Lal R, Olmos D, Molife LR, Kristeleit R, Parker A, Casamayor I, Olaleye M, Mais A, et al: First-inhuman, pharmacokinetic and pharmacodynamic phase I study of Resminostat, an oral histone deacetylase inhibitor, in patients with advanced solid tumors. Clin Cancer Res 19: 5494-5504, 2013.

46. Kitazono S, Fujiwara Y, Nakamichi S, Mizugaki H, Nokihara H, Yamamoto N, Yamada Y, Inukai E, Nakamura O and Tamura T: A phase I study of resminostat in Japanese patients with advanced solid tumors. Cancer Chemother Pharmacol 75: 1155-1161, 2015.

47. Weiland T, Lampe J, Essmann F, Venturelli S, Berger A Bossow S, Berchtold S, Schulze-Osthoff K, Lauer UM and Bitzer M.: Enhanced killing of therapy-induced senescent tumor cells by oncolytic measles vaccine viruses. Int J Cancer 134: $235-243,2014$
48. Spearman C: The method of 'right and wrong cases' ('constant stimuli') without gauss's formulae. Br J Psychol 2: 227-242, 1908.

49. Kärber G: Beitrag zur kollektiven behandlung pharmakologischer reihenversuche. Naunyn Schmiedebergs. Arch Exp Pathol Pharmakol 162: 480-483, 1931. (In German)

50. Walewski J, Pszkiewicz-Kozik E, Warzewska A, Borsaru G, Moicean A, Hellmann A, Mayer J, Hauns B, Mais A, Henning SW, et al: Final results of the phase II SAPHIRE trial of resminostat (4SC-201) in patients with relapsed/refractory Hodgkin lymphoma. Presented at 53rd ASH Annual Meeting and Exposition. (abstract 2675), 2011. http://www.4sc.de/ wp-content/uploads/SAPHIRE-Poster-ASH-San-Diego-2011. pdf.

51. Abassi YA, Xi B, Zhang W, Ye P, Kirstein SL, Gaylord MR, Feinstein SC, Wang X and Xu X: Kinetic cell-based morphological screening: Prediction of mechanism of compound action and off-target effects. Chem Biol 16: 712-723, 2009.

52. Weiland T, Berger A, Essmann F, Lauer UM, Bitzer M and Venturelli S: Kinetic tracking of therapy-induced senescence using the real-time cell analyzer single plate system. Assay Drug Dev Technol 10: 289-295, 2012

53. Stojdl DF, Lichty BD, tenOever BR, Paterson JM, Power AT, Knowles S, Marius R, Reynard J, Poliquin L, Atkins H, et al: VSV strains with defects in their ability to shutdown innate immunity are potent systemic anti-cancer agents. Cancer Cell 4: 263-275, 2003.

54. Abend A and Kehat I: Histone deacetylases as therapeutic targets - from cancer to cardiac disease. Pharmacol Ther 147: 55-62, 2015.

55. Mottamal M, Zheng S, Huang TL and Wang G: Histone deacetylase inhibitors in clinical studies as templates for new anticancer agents. Molecules 20: 3898-3941, 2015.

56. Feng W, Zhang B, Cai D and Zou X: Therapeutic potential of histone deacetylase inhibitors in pancreatic cancer. Cancer Lett 347: 183-190, 2014

57. Xu C, Li H, Su C and Li Z: Viral therapy for pancreatic cancer: Tackle the bad guys with poison. Cancer Lett 333: 1-8, 2013.

58. Honda K, Takaoka A and Taniguchi T: Type I interferon [corrected] gene induction by the interferon regulatory factor family of transcription factors. Immunity 25: 349-360, 2006.

59. Nguyên TL, Abdelbary H, Arguello M, Breitbach C, Leveille S, Diallo JS, Yasmeen A, Bismar TA, Kirn D, Falls T, et al: Chemical targeting of the innate antiviral response by histone deacetylase inhibitors renders refractory cancers sensitive to viral oncolysis. Proc Natl Acad Sci USA 105: 14981-14986, 2008.

60. Fuertes MB, Kacha AK, Kline J, Woo SR, Kranz DM, Murphy KM and Gajewski TF: Host type I IFN signals are required for antitumor $\mathrm{CD}^{+} \mathrm{T}$ cell responses through CD8\{alpha ${ }^{+}$dendritic cells. J Exp Med 208: 2005-2016, 2011.

61. Prestwich RJ, Errington F, Diaz RM, Pandha HS, Harrington KJ, Melcher AA and Vile RG: The case of oncolytic viruses versus the immune system: Waiting on the judgment of Solomon. Hum Gene Ther 20: 1119-1132, 2009.

62. Katsura T, Iwai S, Ota Y, Shimizu H, Ikuta K and Yura Y: The effects of trichostatin A on the oncolytic ability of herpes simplex virus for oral squamous cell carcinoma cells. Cancer Gene Ther 16: 237-245, 2009.

63. Murrow L and Debnath J: Autophagy as a stress-response and quality-control mechanism: Implications for cell injury and human disease. Annu Rev Pathol 8: 105-137, 2013.

64. Yang S, Wang X, Contino G, Liesa M, Sahin E, Ying H, Bause A, Li Y, Stommel JM, Dell'antonio G, et al: Pancreatic cancers require autophagy for tumor growth. Genes Dev 25: 717-729, 2011.

65. White E and DiPaola RS: The double-edged sword of autophagy modulation in cancer. Clin Cancer Res 15: 5308-5316, 2009.

66. Gammoh N, Lam D, Puente C, Ganley I, Marks PA and Jiang X: Role of autophagy in histone deacetylase inhibitor-induced apoptotic and nonapoptotic cell death. Proc Natl Acad Sci USA 109: 6561-6565, 2012.

67. Hristov G, Krämer M, Li J, El-Andaloussi N, Mora R, Daeffler L, Zentgraf $\mathrm{H}$, Rommelaere $\mathrm{J}$ and Marchini A: Through its nonstructural protein NS1, parvovirus H-1 induces apoptosis via accumulation of reactive oxygen species. J Virol 84: 5909-5922, 2010.

68. Kaufman HL, Kohlhapp FJ and Zloza A: Oncolytic viruses: A new class of immunotherapy drugs. Nat Rev Drug Discov 14: 642-662, 2015 
69. Gujar S, Dielschneider R, Clements D, Helson E, Shmulevitz M, Marcato P, Pan D, Pan L, Ahn D-G, Alawadhi A, et al: Multifaceted therapeutic targeting of ovarian peritoneal carcinomatosis through virus-induced immunomodulation. Mol Ther 21: 338-347, 2013

70. Moehler MH, Zeidler M, Wilsberg V, Cornelis JJ, Woelfel T, Rommelaere J, Galle PR and Heike M: Parvovirus H-1-induced tumor cell death enhances human immune response in vitro via increased phagocytosis, maturation, and cross-presentation by dendritic cells. Hum Gene Ther 16: 996-1005, 2005.
71. Kroesen M, Gielen P, Brok IC, Armandari I, Hoogerbrugge PM and Adema GJ: HDAC inhibitors and immunotherapy; a double edged sword? Oncotarget 5: 6558-6572, 2014.

72. Setiadi AF, Omilusik K, David MD, Seipp RP, Hartikainen J, Gopaul R, Choi KB and Jefferies WA: Epigenetic enhancement of antigen processing and presentation promotes immune recognition of tumors. Cancer Res 68: 9601-9607, 2008. 